\title{
Aerosol number fluxes over the Amazon rain forest during the wet
}

\section{season}

\author{
L. Ahlm ${ }^{1}$, E. D. Nilsson ${ }^{1}$, R. Krejci ${ }^{1}$, E. M. Mårtensson ${ }^{1}$, M. $\operatorname{Vogt}^{1}$, and P. Artaxo ${ }^{2}$ \\ ${ }^{1}$ Department of Applied Environmental Science, Stockholm University, Sweden \\ ${ }^{2}$ Institute of Physics, University of São Paulo, Brazil
}

Received: 17 June 2009 - Published in Atmos. Chem. Phys. Discuss.: 19 August 2009

Revised: 27 November 2009 - Accepted: 30 November 2009 - Published: 15 December 2009

\begin{abstract}
Number fluxes of particles with diameter larger than $10 \mathrm{~nm}$ were measured with the eddy covariance method over the Amazon rain forest during the wet season as part of the LBA (The Large Scale Biosphere Atmosphere Experiment in Amazonia) campaign 2008. The primary goal was to investigate whether sources or sinks dominate the aerosol number flux in the tropical rain forest-atmosphere system.

During the measurement campaign, from 12 March to 18 May, $60 \%$ of the particle fluxes pointed downward, which is a similar fraction to what has been observed over boreal forests. The net deposition flux prevailed even in the absolute cleanest atmospheric conditions during the campaign and therefore cannot be explained only by deposition of anthropogenic particles. The particle transfer velocity $v_{t}$ increased with increasing friction velocity and the relation is described by the equation $v_{t}=2.4 \times 10^{-3} \times u_{*}$ where $u_{*}$ is the friction velocity.

Upward particle fluxes often appeared in the morning hours and seem to a large extent to be an effect of entrainment fluxes into a growing mixed layer rather than primary aerosol emission. In general, the number source of primary aerosol particles within the footprint area of the measurements was small, possibly because the measured particle number fluxes reflect mostly particles less than approximately $200 \mathrm{~nm}$. This is an indication that the contribution of primary biogenic aerosol particles to the aerosol population in the Amazon boundary layer may be low in terms of number concentrations. However, the possibility of horizontal variations in primary aerosol emission over the Amazon rain forest cannot be ruled out.
\end{abstract}

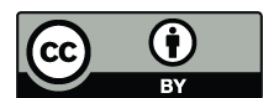

Correspondence to: L. Ahlm

(lars.ahlm@itm.su.se)

\section{Introduction}

The Amazonian forest is the largest tropical forest on Earth covering an area of about 4.7 million $\mathrm{km}^{2}$. The forest has a large influence on the regional and global climate. Evapotranspiration from the Amazonian forest is responsible for $25-50 \%$ of the region's rainfall (Eltahir and Bras, 1996; Li and $\mathrm{Fu}, 2004$ ) and the huge amount of energy used for evapotranspiration is an important regulator of surface temperature. The large areas of highly productive ecosystems in the Amazon are global sources of natural and anthropogenic aerosols and trace gases. With changes in land use and increased human activity in Amazonia (Nepstad et al., 1999), the exchange of energy, gases and aerosols between surface and atmosphere is being perturbed (Davidson and Artaxo, 2004).

Atmospheric aerosols influence climate directly by absorbing and scattering incoming solar radiation, and indirectly by acting as cloud condensation nuclei $(\mathrm{CCN})$, and thereby affecting the cloud microphysical and optical properties, precipitation rate and cloud lifetime (Twomey, 1977; Rosenfeld 2000). In Amazonia, it was shown that aerosol particles strongly influence the radiation balance, affecting the photosynthetic rates and consequently the regional carbon balance (Oliveira et al., 2007). Many studies in the past have focused on biomass burning aerosol characterization over the Amazon (Andreae et al., 2004; Crutzen and Andreae, 1990; Artaxo et al., 1994) but fewer studies deal with the natural biogenic aerosol component. However, to understand the combined influence from anthropogenic biomass burning and deforestation on the Amazon and other tropical rain forests, it is necessary to understand the processes that regulate emission, deposition and properties of natural biogenic aerosols (Artaxo et al., 1990; Artaxo and Hansson, 1995).

Published by Copernicus Publications on behalf of the European Geosciences Union. 
The aerosol mass over the Amazon basin is dominated by organic compounds which on average constitute a fraction of 70 to $90 \%$ both in the fine mode and coarse mode (Andreae and Crutzen, 1997; Graham et al., 2003). During the wet season when biomass burning is suppressed by intense precipitation and the wet removal of aerosols is strong, the high organic fraction must be attributed to natural biogenic sources (Guyon et al., 2003a, b). However, the sources and formation mechanisms are still poorly understood (Artaxo et al., 1994; Graham et al., 2003). In particular, the relative contribution of primary and secondary aerosols to the aerosol population remains largely unknown (Martin et al., 2009). Either of these particles could have an important role in nucleating cloud droplets (Prenni et al., 2007, 2009), being in general efficient CCN (Sun and Ariya, 2006; Gunthe et al., 2009).

Primary biogenic aerosols consist of many different species including pollen, spores, bacteria, algae, protozoa, fungi, fragments of leaves and insects (Artaxo and Hansson, 1995). Concerning fine mode secondary aerosol particles, the emissions of volatile organic compounds (VOC) by natural vegetation plays an important role in the fine mode particle population (Kesselmeier et al., 1999; Claeys et al., 2004). There is little evidence of new particle formation within the boundary layer over the Amazon basin (Rissler et al., 2006). Field observations have shown infrequent occurrence of nucleation mode aerosol in the boundary layer (Rissler et al., 2004) and in a narrow band on top of a growing mixed layer (Krejci et al., 2005b). The outflow regions of deep convective clouds are generally considered to be favorable environments for new particle formation (Ekman et al., 2008) and aircraft measurements have shown that the number of ultrafine particles is at maximum in the middle and upper free troposphere (Krejci et al., 2003). Increased concentrations of newly formed particles were observed also in the outflow of shallow convective clouds over the Amazon (Krejci et al., 2005b). Some of these particles should be able to reach the mixed layer by subsidence and entrainment and consequently grow by coagulation and condensation.

The most direct way of investigating the magnitude of aerosol net exchange between surface and atmosphere is to use the eddy covariance method. A net upward flux could indicate that there is an emission that dominates over the dry deposition sink (Nilsson et al., 2001a; Mårtensson et al., 2006). However, also entrainment of cleaner air from above during mixed layer growth may temporarily produce upward fluxes (Nilsson et al., 2001b). A net downward flux on the other hand could, during periods with negligible influence from aerosol sources outside the forest-atmosphere system, indicate that there are high numbers of particles that have been formed within the atmosphere. Eddy covariance measurements over boreal forests have shown high correlation between new particle formation events in the boundary layer and strong downward particle fluxes (Buzorius et al., 2001; Nilsson et al., 2001b). If new particle formation is tak- ing place in the tropical free troposphere, these particles first need to descend through the free troposphere to be entrained into the mixed layer. Once they reach the boundary layer, a fraction of them will be removed by dry deposition. Hence, the dry deposition of primary and secondary natural aerosol particles formed or emitted within the forest-atmosphere system and the dry deposition of particles that have been transported from outside the system both contribute to the downward particle flux, which competes with the primary aerosol emission for the overall sign of the vertical aerosol flux.

In this project we have measured vertical turbulent fluxes of aerosols, $\mathrm{CO}_{2}$ and sensible and latent heat to explore links between aerosol fluxes and the behavior of the forest and the atmosphere. This Brazilian-Swedish project AMAFLUX (Amazonian Biosphere-Atmosphere Aerosol Fluxes in view of their potential control of cloud properties and climate) was carried out as a part of the larger international project LBA (The Large Scale Biosphere Atmosphere Experiment in Amazonia). The fieldwork was divided into two parts. The first part took place from the middle of March to middle of May 2008, which represents wet season and the second period took place between early July and middle of August 2008, which represents dry season. Here we treat the first period when the interactions between forest and atmosphere are expected to be controlled to a large extent by natural processes. The objective is to examine if sinks or sources dominate the aerosol number flux and to deduce as much as possible about the processes involved.

\section{Methods and site}

\subsection{Site description}

The measurements were carried out at the top of the 53 meter high tower K34 in the Reserva Biológica do Cuieiras $\left(2^{\circ} 35.37^{\prime} \mathrm{S}, 60^{\circ} 06.92^{\prime} \mathrm{W}\right)$, approximately $60 \mathrm{~km} \mathrm{NNW}$ of Manaus, Brazil. The tower is maintained by INPA (The Brazilian National Institute for Research in Amazonia). Figure 1 shows the location of the measurement site. The city of Manaus is located more than $1000 \mathrm{~km}$ inland from the Atlantic Ocean and has a population of $\sim 1.7$ million people. Average annual rainfall in the region is $2200 \mathrm{~mm}$ with two marked seasons (November-May wet season; June-October dry season). Although highly variable, rainfall is present throughout the year. The prevailing easterly trade winds blow over large areas of undisturbed rain forest before reaching the Cuieiras Reserve (Andreae et al., 2002). However, the influence of emissions from the urban area of Manaus becomes evident when the southerly wind component increases.

The canopy height in the Cuieiras Reserve is between 30 and $35 \mathrm{~m}$ (Kruijt et al., 2000) and the leaf area index has been estimated to be $5-6 \mathrm{~m}^{2} \mathrm{~m}^{-2}$ (McWilliam et al., 1993). The $\mathrm{K} 34$ flux tower is a $1.5 \mathrm{~m} \times 2.5 \mathrm{~m}$-section aluminum tower standing on a medium sized plateau $130 \mathrm{~m}$ a.s.l. (Araújo et 


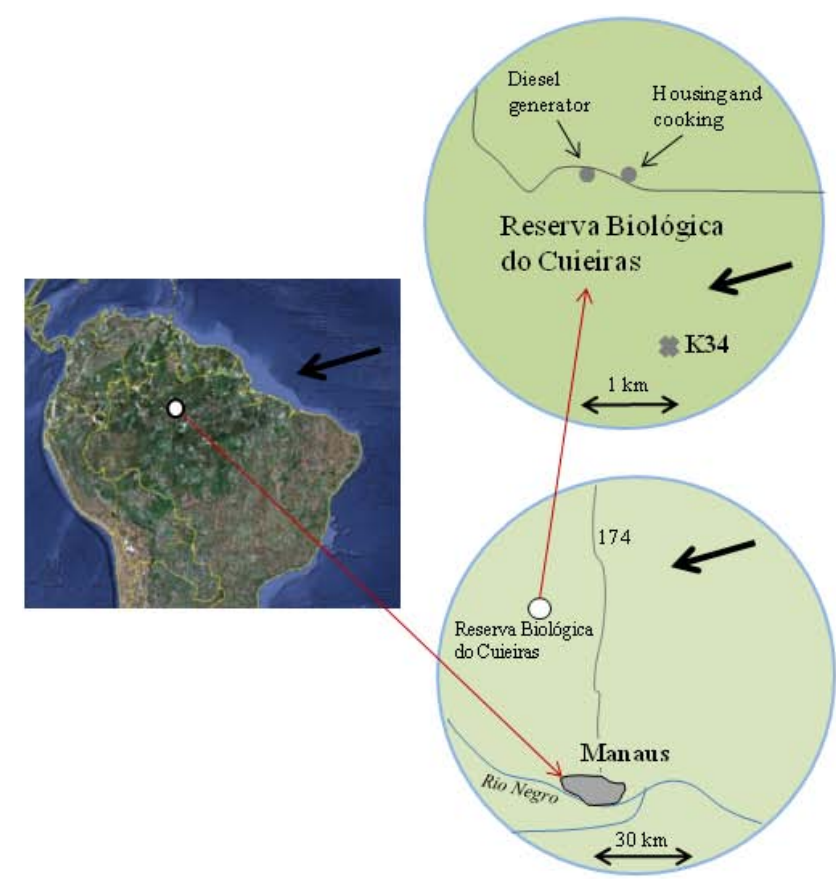

Fig. 1. Overview map of the measurement site in the Reserva Biológica do Cuieiras. The black arrows show the most common wind direction during March to May - wet season. The map over northern South America to the left is taken from Google Earth.

al., 2002; Campos et al., 2009). A diesel generator is located more than $2 \mathrm{~km}$ northwest of K34 providing the research station with electricity. There is also a field station house at the center of the research area $\sim 2 \mathrm{~km}$ north of K34. Both the generator and the house could possibly affect the particle concentrations at $\mathrm{K} 34$ when prevailing wind direction is between north and northwest. The road BR-174 (Fig. 1) goes from Manaus northwards to Venezuela and passes the Cuieiras Reserve on the east side at a distance of about $19 \mathrm{~km}$. Long distance trucks use this road but it is not densely trafficked.

\subsection{Eddy covariance}

The vertical aerosol number flux was calculated with the eddy covariance technique. The aerosol number concentration $N$ and the vertical wind speed $w$ can be divided into means and fluctuations from the mean, $N=\bar{N}+N^{\prime}$ and $w=\bar{w}+w^{\prime}$. By following the Reynold's averaging rules, it can be shown that $\overline{N w}=\bar{N} \bar{w}+\overline{N^{\prime} w^{\prime}}$ where $\bar{N} \bar{w}$ is the vertical advective flux and $\overline{N^{\prime} w^{\prime}}$ is the vertical turbulent flux. The vertical advection is assumed to be a result of the terrain and therefore the coordinate system is rotated in order to obtain zero vertical advection. Then the total vertical flux becomes equal to the turbulent vertical flux.

For this study the vertical aerosol flux $\overline{N^{\prime} w^{\prime}}$ was calculated over periods of $30 \mathrm{~min}$. The fluctuations $N^{\prime}$ and $w^{\prime}$ were separated from the mean by linear de-trending, which also removes the influence of low frequency trends. The aerosol data was shifted in relation to the wind data to correct for the time lag in the sampling line (calculated from the maximum correlation). Turbulent fluxes of momentum, sensible and latent heat and $\mathrm{CO}_{2}$ were calculated in a similar way.

Finnigan et al. (2003) investigated how the flux magnitude depends on choice of averaging period at a $46.5 \mathrm{~m}$ high tower in the Cuieiras Reserve. Fluxes of sensible heat, latent heat and $\mathrm{CO}_{2}$ were calculated for averaging periods of $15 \mathrm{~min}$ and 1, 2, 3, 4 and $8 \mathrm{~h}$. They found that the fluxes increased in magnitude with increasing averaging period up to $3 \mathrm{~h}$ but at even longer averaging periods little further increase was observed. The low frequency motions were interpreted as a result of the deep convective boundary layer.

However, the variability in aerosol particle concentration is much larger than the variability in temperature, water vapor and $\mathrm{CO}_{2}$ concentration. To de-trend the particle concentrations over longer time intervals will often produce large errors and increase the uncertainty of the flux. Furthermore, the focus in this study is to a higher extent on the sign of the particle flux than on the magnitude of the flux. Therefore we have chosen to calculate the fluxes over periods of $30 \mathrm{~min}$, well aware of that this is a compromise.

\subsection{Instrumentation}

\subsubsection{Flux measurements}

The 3-D wind components and temperature were measured with a Gill Windmaster ultrasonic anemometer, and logged at $20 \mathrm{~Hz}$. To measure the total aerosol number concentration (particle diameter $\mathrm{D}_{p}>10 \mathrm{~nm}$ ) we used a Condensation Particle Counter (CPC), model TSI 3010, which was logged at $1 \mathrm{~Hz}$. The aerosol was sampled just beneath the sonic head through a $4 \mathrm{~m}$ long $1 / 4$-inch stainless steel sampling line. The sampling flow through the $\mathrm{CPC}$ was $1.021 \mathrm{~min}^{-1}$.

Concentrations of $\mathrm{CO}_{2}$ and $\mathrm{H}_{2} \mathrm{O}$ were measured by a Li7500 Open Path Analyzer. The Licor was logged both as digital RS232 signals through an EDG-4508 gateway and as analog signals through the Gill windmaster auxiliary input channels, in both cases at $20 \mathrm{~Hz}$.

The most frequent technical problem encountered during the campaign was condensation of water vapor inside the CPC saturator. Therefore the CPC reservoir had to be drained and thereafter filled with new butanol more or less every day. This problem was related to the high water content of the air and was more problematic than we have experienced before even in marine environments.

\subsubsection{Additional measurements used during data anal- ysis}

Mass concentration of equivalent black carbon $\left(\mathrm{BC}_{\mathrm{e}}\right)$ was provided by São Paulo University using a Multi-Angle 
Absorption Photometer (MAAP). This measurement derives the concentration of $\mathrm{BC}_{\mathrm{e}}$ from the determination of light absorption at a wavelength of $670 \mathrm{~nm}$ using an empirical mass absorption efficiency of $6.5 \mathrm{~m}^{2} \mathrm{~g}^{-1}$. Because of uncertainties regarding the appropriate value of the mass absorption efficiency and the possibility of contributions from lightabsorbing organic aerosols, we chose the term $\mathrm{BC}_{\mathrm{e}}$ to reflect the operational definition of this measurement (Andreae and Gelencsér, 2006). $\mathrm{BC}_{\mathrm{e}}$ was measured at a container close to the house at the center of the research station, approximately $2 \mathrm{~km}$ north of $\mathrm{K} 34$.

Additionally, mass concentrations of trace elements were provided by São Paulo University using particle-induced X ray emission analysis (PIXE). The sampling for the PIXE trace element analysis was also made at the container.

Meteorological parameters (temperature, relative humidity, rain amounts and photosynthetic active radiation) were measured at the K34 tower and provided by INPA. These were logged on a Campbell CR-10 (Campbell Scientific UK) data logger with a sampling interval of 30 seconds and stored as either 10 or $30 \mathrm{~min}$ averages.

\subsection{Flux corrections}

\subsubsection{Effects of limited instrumental frequency response}

The underestimation of the particle flux due to limited time response depends on the frequency of the turbulence. It can approximately be determined by the observation level $z$ (53 m), mean horizontal wind speed $\bar{U}$ and stratification $z / L$, where $L$ is the Obukhov length. The underestimation in the flux can be estimated according to (Buzorius et al., 2003) as

$$
\frac{F_{m}}{F}=\frac{1}{1+\left(2 \pi n_{m} \tau_{c} \bar{U} / z\right)^{\alpha}}
$$

with $\alpha=1$ for $z / L>0$ (stable stratification) and $\alpha=7 / 8$ for $z / L \leq 0$ (neutral and unstable stratification). The normalized frequency, $n_{m}$, equals 0.085 for $z / L \leq 0$ and

$n_{m}=2.0-\frac{1.915}{1+0.5 \frac{z}{L}}$ for $z / L>0$.

The frequency first order response time constant $\tau_{c}$ of the TSI 3010 has been estimated to $0.8 \mathrm{~s}$ (Doebelin, 1990). However, in this study the particle concentration was measured at a frequency of $1 \mathrm{~Hz}$ and therefore a value of $1 \mathrm{~s}$ on $\tau_{c}$ has been used in Eq. (1).

All aerosol fluxes presented in this work have been corrected according to Eqs. (1) and (2). The correction when using these equations on average was $13 \%$ of the measured net aerosol flux in this study.

\subsubsection{Webb-correction}

The assumption behind the Webb correction is that the vertical mass flux of dry air is zero:

$\overline{w \rho_{a}}=0$

where $w$ is the vertical wind speed and $\rho_{a}$ is the density of dry air. At least in a non-stable surface layer, ascending air on average will be warmer, containing more water vapor (and thereby having lower density) than descending air. Therefore the mean of the vertical wind speed $\bar{w}$ usually must be positive for the mass flux of dry air to be zero. A positive $\bar{w}$ produces a positive vertical advection term that must be added to the measured turbulent flux. This correction is known as the Webb correction and is most important when heat fluxes are large which is the case in a convective boundary layer. The impact from the sensible heat flux is more important than the corresponding impact from the latent heat flux.

Webb et al. (1980) showed that

$\bar{w}=1.61 \frac{\overline{w^{\prime} \rho_{v}^{\prime}}}{\overline{\rho_{a}}}+(1+1.61 \bar{q}) \frac{\overline{w^{\prime} T^{\prime}}}{\bar{T}}$

where $\rho^{\prime}{ }_{v}$ is fluctuation in density of water vapor, $\bar{q}$ is the averaged specific humidity and $\bar{T}$ is the average and $T^{\prime}$ the fluctuating part of the temperature.

From Eq. (4) follows that the total flux $F$ of the substance $c$ is

$F=\overline{w^{\prime} c^{\prime}}+1.61 \frac{\overline{w^{\prime} \rho_{v}^{\prime}}}{\overline{\rho_{a}}}+(1+1.61 \bar{q}) \frac{\overline{w^{\prime} T^{\prime}}}{\bar{T}} \bar{c}$

where $\bar{c}$ is the average and $c^{\prime}$ the fluctuating part of the concentration of the substance. In this study, the Webb correction has been applied for the $\mathrm{CO}_{2}$ and the latent heat flux. The Webb correction at noon (when energy fluxes are at maximum) reduced the net downward $\mathrm{CO}_{2}$ flux by $\sim 25 \%$ and increased the latent heat flux by $\sim 9 \%$.

The situation is more complicated for particle fluxes. Temperature fluctuations are dampened in a tubing of several meters (Rannik et al., 1997). Probably even more important, inside the CPC the air is both heated and cooled, as part of the detection process, before the flow rate is set by the critical orifice inside the CPC. Therefore no correction of particle fluxes due to sensible heat fluxes was applied. Concerning water vapor, a fraction of the water vapor entering the CPC inlet is deposited in the butanol in the CPC reservoir before the particles are being counted and the flow rate is set inside the CPC. It is hard to estimate what fraction of water vapor flowing into the CPC that is trapped there, but during this campaign it seems to have been a significant amount. Therefore neither any Webb correction due to latent heat fluxes was applied to the particle fluxes. 

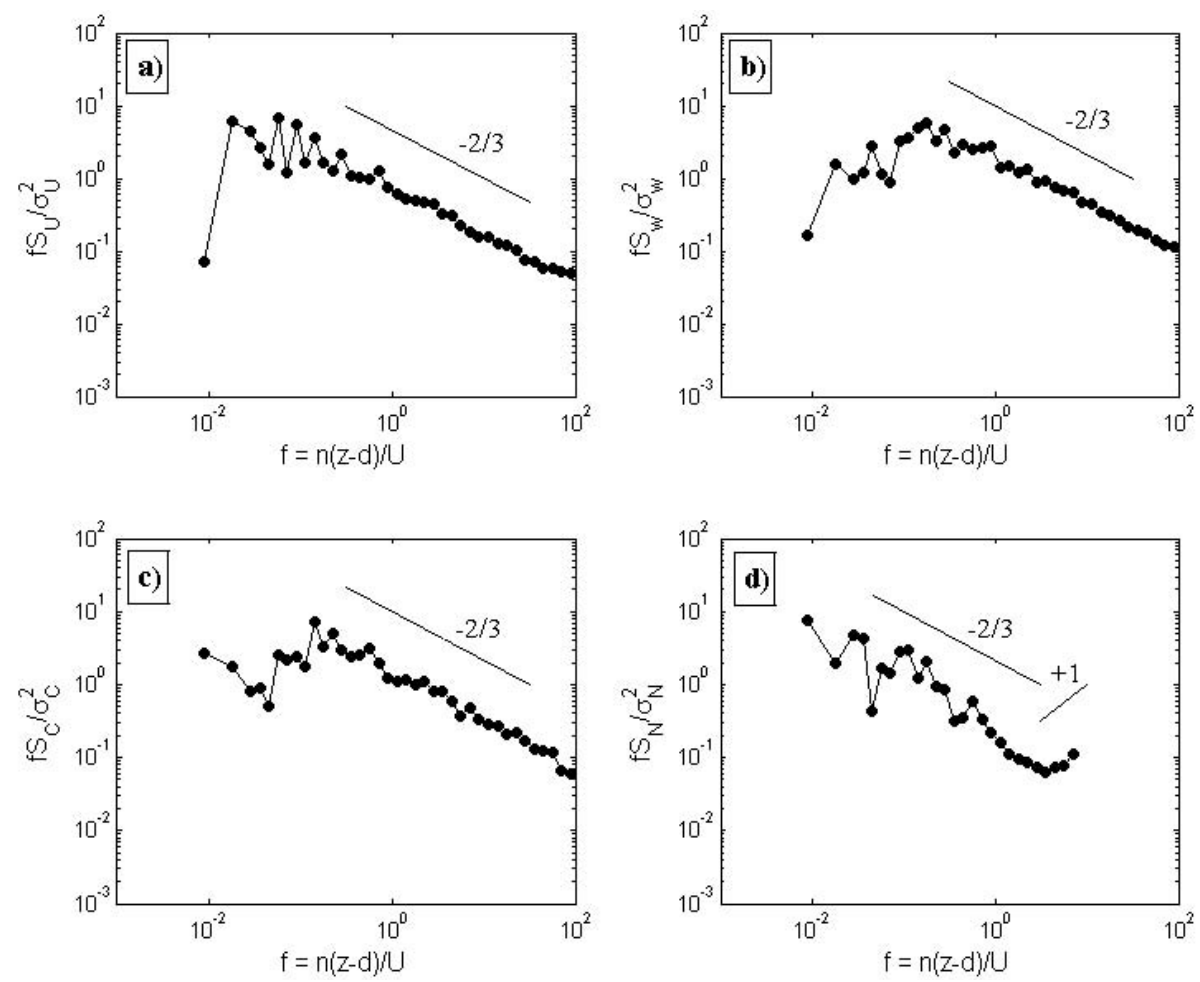

Fig. 2. Averaged frequency weighted spectral densities $(S)$ normalized with the variance $(\sigma)$ plotted against dimensionless frequency $(f)$ for (a) horizontal wind speed $(U)$, (b) vertical wind speed $(w)$, (c) $\mathrm{CO}_{2}$ concentration $(\mathrm{c})$ and $(\mathrm{d})$ particle number concentration $(N)$. Data were collected between 11:00 and 11:30 LT on 13 March. The $-2 / 3$ slope is the theoretical decay within the inertial subrange.

\subsection{Error treatment}

Following Buzorius et al. (2003), the uncertainty in the flux due to discrete counting can be expressed as

$\delta\left(N^{\prime} w^{\prime}\right)=\frac{\sigma_{w} \bar{N}}{\sqrt{\bar{N} Q \Delta t}}$

where $\sigma_{w}$ is the standard deviation of the vertical wind, $\bar{N}$ is the aerosol number concentration averaged over the sampling period $\Delta t$ (in our case $30 \mathrm{~min}$ ) and $Q$ is the sampling volume flow rate through the particle counter. When considering relative errors, high turbulence and number concentrations usually correspond to high aerosol number fluxes, so the relative error may actually decrease with increasing $\bar{N}$ and $\sigma_{w}$, and vice versa. The average uncertainty in particle flux due to discrete counting was in this study about $5 \%$.

\subsection{Turbulence spectra}

Turbulence power spectra and co-spectra were calculated in order to investigate the performance of the eddy correlation system. The spectra were obtained using fast Fourier transform (FFT) to linearly de-trended data over a time period of $30 \mathrm{~min}$. Power spectra and co-spectra presented in next paragraph are frequency weighted and normalized by the vari- ance and the covariance respectively. The normalized frequency weighted spectra are averaged over logarithmically changing intervals and plotted against the non-dimensional frequency

$f=n(z-d) / \bar{U}$

where $n$ is the frequency, $z$ is the measurement height, $d$ is the displacement height (assumed to be 2/3 of the canopy height) and $\bar{U}$ is the average horizontal wind speed over the time interval.

There are limitations within this section as to how many spectra can be shown. However, spectra involving all instruments are shown here and discussed. Figure 2 shows samples of averaged power spectra of horizontal wind speed (a), vertical wind speed (b), $\mathrm{CO}_{2}$ concentration (c) and particle concentration (d). The particle spectrum does not cover as high frequencies as the wind and $\mathrm{CO}_{2}$ spectra since the particle concentration was sampled at $1 \mathrm{~Hz}$ by the CPC compared to $20 \mathrm{~Hz}$ sampling frequency for wind and $\mathrm{CO}_{2}$. Data were collected between 11:00-11:30 LT (local time) on 13 March. Stability index $z / L$ was -0.80 , hence unstable conditions. The average friction velocity was $0.35 \mathrm{~ms}^{-1}$. The slope in the inertial subrange follows quite well the $-2 / 3$ power law for all the four spectra. However, the aerosol power spectrum exhibited a slightly faster decay than the $-2 / 3$ slope. This 

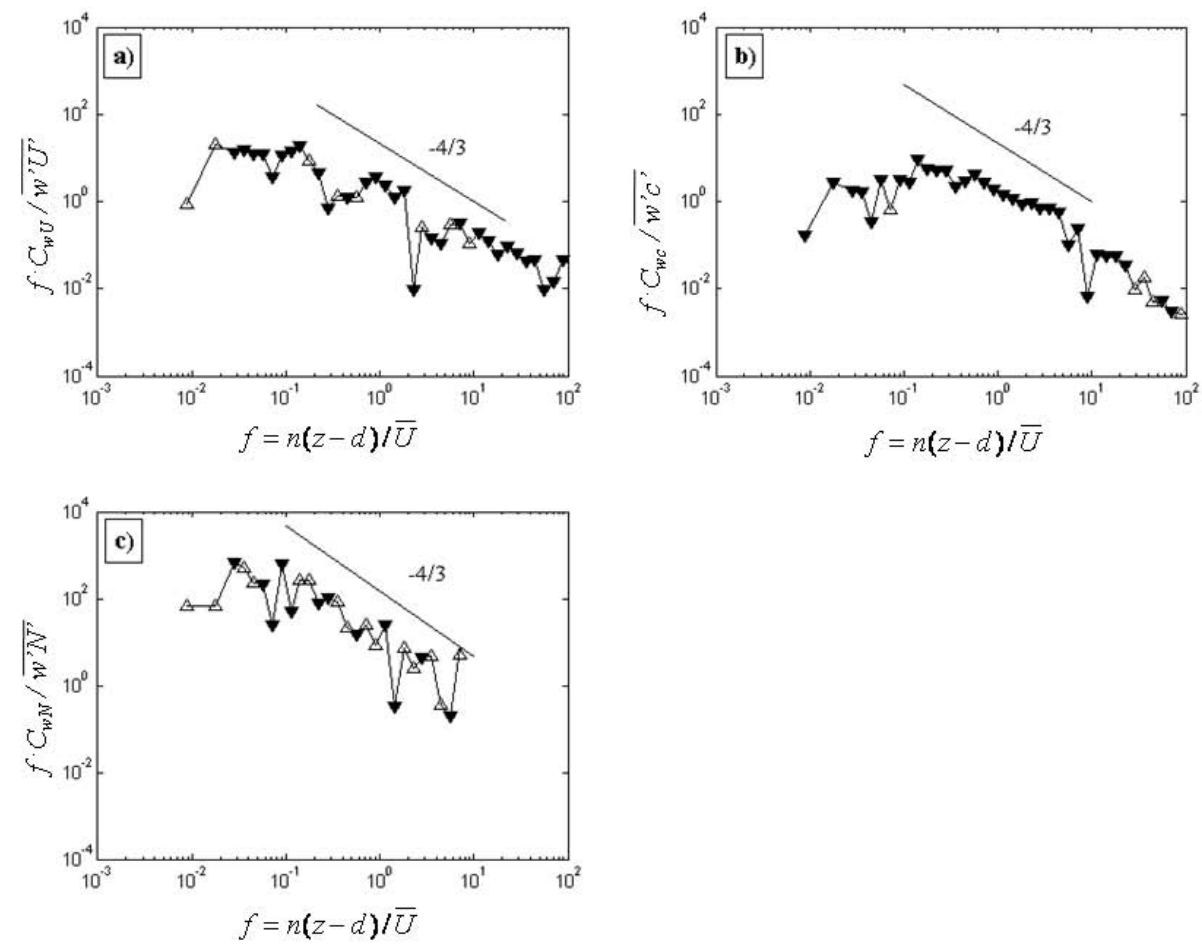

Fig. 3. Averaged frequency weighted co-spectra $(C)$ normalized with the covariance plotted against dimensionless frequency between 11:00 and 11:30 LT on the 13 March for (a) $w$ and $U$, (b) $w$ and $c$ and (c) $w$ and $N$. White triangles pointing upward represent positive co-spectral densities and black triangles pointing downwards are negative co-spectral densities. The $-4 / 3$ slope is the theoretical decay within the inertial subrange.

is most likely due to some attenuation of higher frequencies within the sampling line connected to the CPC. The power spectra of horizontal and vertical wind and $\mathrm{CO}_{2}$ all have a peak in spectral density at the lower frequencies. The particle spectrum, however, does not peak within the frequency range. This is probably due to non-stationary conditions concerning particle concentration since the aerosol number concentration was increasing during this half hour period. For the highest frequencies in the particle spectrum, the spectral density increases with increasing frequency. The slope of this increase is close to +1 which indicates that this is due to white noise.

Figure 3 shows co-spectra for momentum flux (a), $\mathrm{CO}_{2}$ flux (b) and particle flux (c) for the same half hour period as in Fig. 2. All three spectra agree quite well with the $-4 / 3$ power law. The white noise for the particle spectrum in Fig. 2d is not apparent in the co-spectrum (Fig. 3c). Some of the variance spectra for other half hour periods during the campaign had even larger influence from white noise than seen in Fig. 2d but the noise did not have any influence on the co-spectra, which is because there is no correlation between the white noise in the CPC and the vertical wind from the sonic anemometer. As a result, the white noise adds no false flux. Nonetheless, all flux contribution from frequencies higher than the frequency where white noise starts to dominate is lost. To compensate for this, Eq. (1-2) are used.
Figure 4 shows particle spectra for a half hour period with more constant particle concentrations. The data were collected between 14:30 to 15:00 LT on 18 March (also during unstable conditions.) The variance spectrum (Fig. 4a) agrees with $-2 / 3$ power law and the particle flux co-spectrum (Fig. $4 b$ ) agrees with the $-4 / 3$ power law. In this case, when particle concentrations are more constant, the frequencyweighted densities clearly peak within the frequency range. The peak, in both Fig. $4 \mathrm{a}$ and $\mathrm{b}$, is located around $f=0.1$, similarly to the peaks in the power spectra for wind and $\mathrm{CO}_{2}$ (Fig. 2a-c) and in the co-spectra for momentum and $\mathrm{CO}_{2}$ flux (Fig. 3a-b).

Sensible and latent heat flux spectra are not shown here since these are not the most important parameters of this study. However, these spectra in general looked theoretically well.

\section{Results and discussion}

The measurements included in this study were performed between 12 March and 18 May 2008, in the wet season. Concerning the CPC measurements, $37 \%$ of the data had to be removed because of technical problems, mainly linked to water deposition in the CPC butanol reservoir. Of the $\mathrm{CO}_{2}$ and $\mathrm{H}_{2} \mathrm{O}$ measurements, $15 \%$ of the data were rejected, primarily 

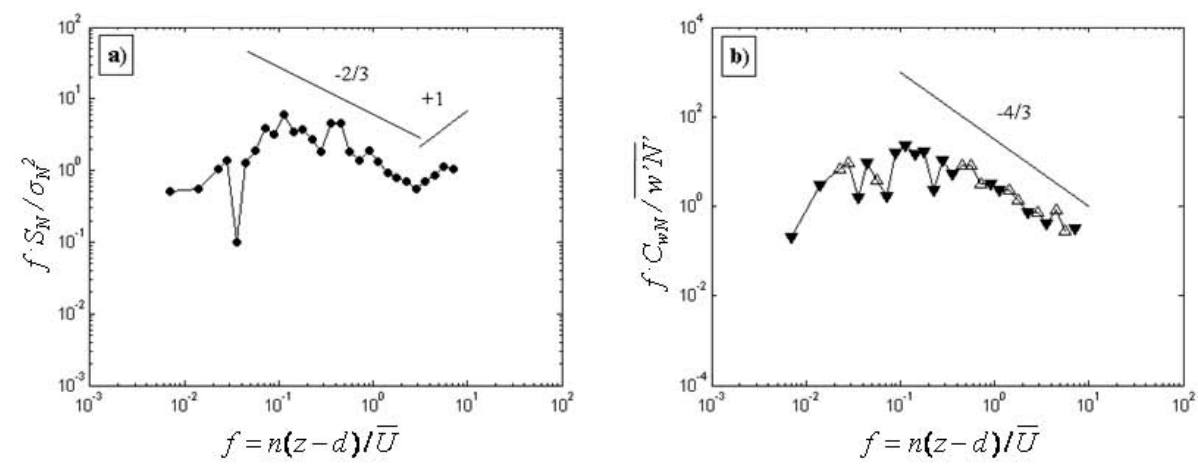

Fig. 4. Averaged normalized frequency weighted spectra for particle concentration variance (a) and particle flux covariance (b) plotted against dimensionless frequency between 14:30 and 15:00 LT on 18 March. White triangles pointing upward represent positive co-spectral densities and black triangles pointing downwards are negative co-spectral densities.

because of problems with electricity and computer software. Meteorological and $\mathrm{BC}_{\mathrm{e}}$ measurements ran more or less continuously during the period. The concentrations of the different compounds have not been converted to STP (standard temperature and pressure) conditions. The reason for this is that the exact temperature when counting the particles inside the CPC was not well known. The condensation temperature inside the CPC was logged but the air will have a somewhat higher temperature when the particles are being counted and the sampling flow rate is set. An estimation of this temperature would produce new errors. For consistency, neither the concentrations of the other compounds have been converted to STP, and represent ambient conditions.

\subsection{Average conditions during the campaign}

Table 1 shows the average conditions during the measurement period. The flux parameters are defined as positive when the flux is upward and negative when the flux is downward.

\subsection{Diurnal cycles of meteorological parameters}

The diurnal cycles (Fig. 5a-g) are shown as medians of halfhour mean values. The reason for choosing median cycles instead of mean cycles is to reduce the weight of extreme values and instead show what is happening more frequently. The only exception is the diurnal cycle of rainfall (Fig. 5h), where it makes more sense to use mean cycle since the median rain amount is zero for a high fraction of the half hour intervals forming the diurnal cycle.

All parameters in Fig. 5 have very distinct diurnal variations driven by the incoming solar radiation. The sunrise was at 06:00 LT and the sunset at 18:00 LT which can be seen in the curve showing Photosynthetic Active Radiation (PAR) in Fig. 5a. The PAR has its maximum a little before noon as a result of gradually increasing convective cloudiness that often occurs during the day and throughout the afternoon. The curves for sensible and latent heat fluxes (Fig. 5b) are well correlated with the PAR.

The latent heat flux is approximately three times larger than the sensible heat flux and reaches on average $250 \mathrm{~W} \mathrm{~m}^{-2}$ at maximum during the day. The temperature (Fig. 5c) reaches on average $28^{\circ} \mathrm{C}$ during daytime but falls to $\sim 23^{\circ} \mathrm{C}$ during nighttime. The relative humidity, anticorrelated with the temperature, reaches almost $100 \%$ at nighttime but falls to around $70 \%$ in daytime.

The diurnal cycle of water vapor molar density (Fig. 5d) reveals much information about the diurnal cycle of the atmospheric boundary layer. During the night, the water vapor concentration gradually decreases because the temperature falls and the relative humidity is at $100 \%$ or just below. This results in a minimum in water vapor concentration around sunrise. From 06:00 to 09:00 LT, the water vapor concentration increases rapidly and this increase can be attributed to increasing evapotranspiration, which can be seen in the latent heat flux curve (also Fig. 5d). The initial mixed layer growth within the stable boundary layer, sometimes referred to as "the burning off" of the nocturnal inversion, is a slow process (Stull, 1988). This means that the water vapor from increasing evapotranspiration during the morning hours is trapped in a shallow and slowly growing layer connected to the surface. Between 09:00 and 15:00 LT, the water vapor concentration instead decreases, a period when a strong upward latent heat flux prevails. Thus, entrainment of dry air from aloft now dominates over evapotranspiration, which indicates that the mixed layer during this period grows much faster. The increase in mixed layer growth rate after 09:00 LT in the morning is a result of that the nocturnal inversion has been defeated and the mixed layer reaches the residual layer above where resistance to further growth is much smaller.

The rapid decrease in water vapor concentration after 09:00 LT does not mean that the mixed layer growth rate is highest during these morning hours. Contrary, Fisch et al. (2004) observed maximum growth rates between 11:00 and 14:00 LT during the wet season over the Amazon rain 
Table 1. Average conditions for critical parameters during the campaign. The \pm range after the mean value is the standard deviation and the numbers after the median are 10 and 90 percentiles. The average diurnal maximum and minimum have been calculated by taking the median value of all diurnal maxima and minima throughout the campaign. The numbers within the brackets in the max and min columns are 10 and 90 percentiles. LAM stands for Low influence of Anthropogenic sources and Mineral dust) and the exact definition is described in Sect. 3.3 .

\begin{tabular}{|c|c|c|c|c|}
\hline & Mean & Median & Diurnal max & Diurnal min \\
\hline Temperature $\left({ }^{\circ} \mathrm{C}\right)$ & $24.6 \pm 2.3$ & $24.0(22.2,28.2)$ & $28.9(26.3,31.0)$ & $22.2(21.6,23.1)$ \\
\hline Relative humidity (\%) & $86.4 \pm 10.6$ & $90.7(69.2,95.9)$ & $96.0(94.7,96.5)$ & $66.1(54.6,78.6)$ \\
\hline Rain amount per day (mm) & $10.8 \pm 12.8$ & $5.6(0.2,29.1)$ & - & - \\
\hline Photosynthetic active radiation $\left(\mathrm{Wm}^{-2}\right)$ & $84.6 \pm 129.7$ & $1.5(0,303.6)$ & $455(275,537)$ & 0 \\
\hline Sensible heat flux $\left(\mathrm{Wm}^{-2}\right)$ & $14.4 \pm 47.2$ & $-0.7(-11.7,77.3)$ & $142.7(36.0,230.6)$ & $-26.7(-102.6,-10.2)$ \\
\hline Water vapor molar density $\left(\mathrm{mmol} \mathrm{m}^{-3}\right)$ & $1120 \pm 170$ & $1140(970,1250)$ & $1246(1160,1606)$ & $834(275,1150)$ \\
\hline Latent heat flux $\left(\mathrm{Wm}^{-2}\right)$ & $71.4 \pm 133.1$ & $11.5(-2.2,254.8)$ & $368(166,489)$ & $-23.1(-116.2,-0.35)$ \\
\hline Wind speed $\left(\mathrm{ms}^{-1}\right)$ & $2.0 \pm 0.9$ & $1.9(0.9,3.0)$ & $3.6(2.7,4.8)$ & $0.4(0.2,1.2)$ \\
\hline Friction Velocity $\left(\mathrm{ms}^{-1}\right)$ & $0.21 \pm 0.16$ & $0.18(0.04,0.42)$ & $0.52(0.35,0.77)$ & $0.018(0.008,0.063)$ \\
\hline Inverted Obukhov length $1 / \mathrm{L}\left(\mathrm{m}^{-1}\right)$ & $0.03 \pm 0.94$ & $0.01(-0.05,0.11)$ & $0.76(0.05,6.05)$ & $-0.31(-6.2,-0.01)$ \\
\hline $\mathrm{CO}_{2}$ molar density $\left(\mathrm{mmol} \mathrm{m}^{-3}\right)$ & $15.6 \pm 1.4$ & $15.4(14.5,17.0)$ & $17.3(15.5,21.3)$ & $14.4(11.7,14.7)$ \\
\hline $\mathrm{CO}_{2}$ flux $\left(\mu \mathrm{mol} \mathrm{m}^{-2} \mathrm{~s}^{-1}\right)$ & $-1.38 \pm 7.37$ & $0.47(-13.15,6.06)$ & $11.3(4.2,17.3)$ & $-17.6(-19.7,-11.2)$ \\
\hline Particle number concentration $\left(\mathrm{cm}^{-3}\right)$ & $682 \pm 780$ & $466(243,1260)$ & $853(445,5338)$ & $263(133,458)$ \\
\hline Particle number flux $\left(10^{6} \mathrm{~m}^{-2} \mathrm{~s}^{-1}\right)$ & $-0.32 \pm 3.50$ & $-0.10(-1.44,1.03)$ & $1.70(0.40,14.3)$ & $-2.41(-20.2,-0.51)$ \\
\hline Particle number concentration LAM $\left(\mathrm{cm}^{-3}\right)$ & $330 \pm 98$ & $333(189,461)$ & $573(386,597)$ & $271(132,461)$ \\
\hline Particle number flux LAM $\left(10^{6} \mathrm{~m}^{-2} \mathrm{~s}^{-1}\right)$ & $-0.08 \pm 1.04$ & $-0.08(-0.78,0.56)$ & $1.18(0.31,4.44)$ & $-1.26(-4.13,-0.24)$ \\
\hline $\mathrm{BC}_{\mathrm{e}}$ concentration $\left(\mathrm{ng} \mathrm{m}^{-3}\right)$ & $80 \pm 45$ & $69(36,140)$ & $131(77,263)$ & $33(21.4,64.1)$ \\
\hline $\mathrm{BC}_{\mathrm{e}}$ concentration LAM $\left(\mathrm{ng} \mathrm{m}^{-3}\right)$ & $52 \pm 15$ & $51(32,74)$ & $77(66,80)$ & $31(21,64)$ \\
\hline
\end{tabular}

forest. However, during this period, the mixed layer usually is rather well developed which reduces the impact from entrainment on the water vapor concentration. The drying effect from entrainment during the evolution of the mixed layer was observed also by Martin et al. (1988). The outflow of water vapor from the mixed layer into convective clouds above also contributes to the drying of the mixed layer (Betts et al., 2002).

After 15:00LT, when the depth of the mixed layer is often close to constant and at its maximum around $1 \mathrm{~km}$ (Fisch et al., 2004), the water vapor concentration again increases. Around 17:00 LT, a stable nocturnal boundary layers starts to develop which can be seen in the negative sensible heat flux in Fig. 5b and the stability in Fig. 5e. It reaches on average a final depth of 80-180 m (Garstang et al., 1990). The water vapor concentration continues to increase until 21:00 LT, which indicates that evaporation continues at decreasing intensity well after sunset. Even a low evaporation rate can have a relatively large impact on the water vapor concentration in the shallow nocturnal boundary layer.

Fig. 5e shows the diurnal cycle of the stability. In general, the stratification is stable at nighttime and unstable in daytime. The stability starts decreasing immediately after sunrise. Horizontal wind speed and friction velocity (Fig. 5f) are higher in daytime than at nighttime. Rainfall (Fig. $5 \mathrm{~g}$ ) is present during the wet season at all times of the day but on average the maximum amounts come during after- noon. Wind directions between east and northeast dominate (Fig. 5h), both in daytime (Fig. 5i) and at nighttime (Fig. 5j). The daytime wind direction distribution has larger variability than the nighttime distribution, probably due to more influence from convective cloud systems.

\subsection{Anthropogenic influence on aerosol number concentrations and fluxes at $\mathrm{K34}$}

The atmospheric boundary layer over the Amazon rain forest in the wet season represents among the cleanest continental conditions that can be found on Earth, close to aerosol number concentrations over remote oceans (Andreae at al., 2009). One of the key motivations for wet season field measurement campaigns in the Amazon basin during the last 20 years has been to use the basin as a laboratory to study pristine continental aerosol particles (Martin et al., 2009). However, even during the wet season anthropogenic sources may occasionally have an influence on the aerosol population in the vicinity of the K34 tower. Figure 6 shows how the aerosol number concentration (Fig. 6a) and flux (Fig. 6b) vary with wind direction. Each bin is a median of all data within that specific 10 degree wide wind direction interval. The number concentration has a rather broad peak with its center around $150^{\circ}$. This is the approximate direction to the city of Manaus. The maximum downward fluxes are located in the same wind sector as the peak in number concentration. This means that there is net deposition when winds are coming from this 

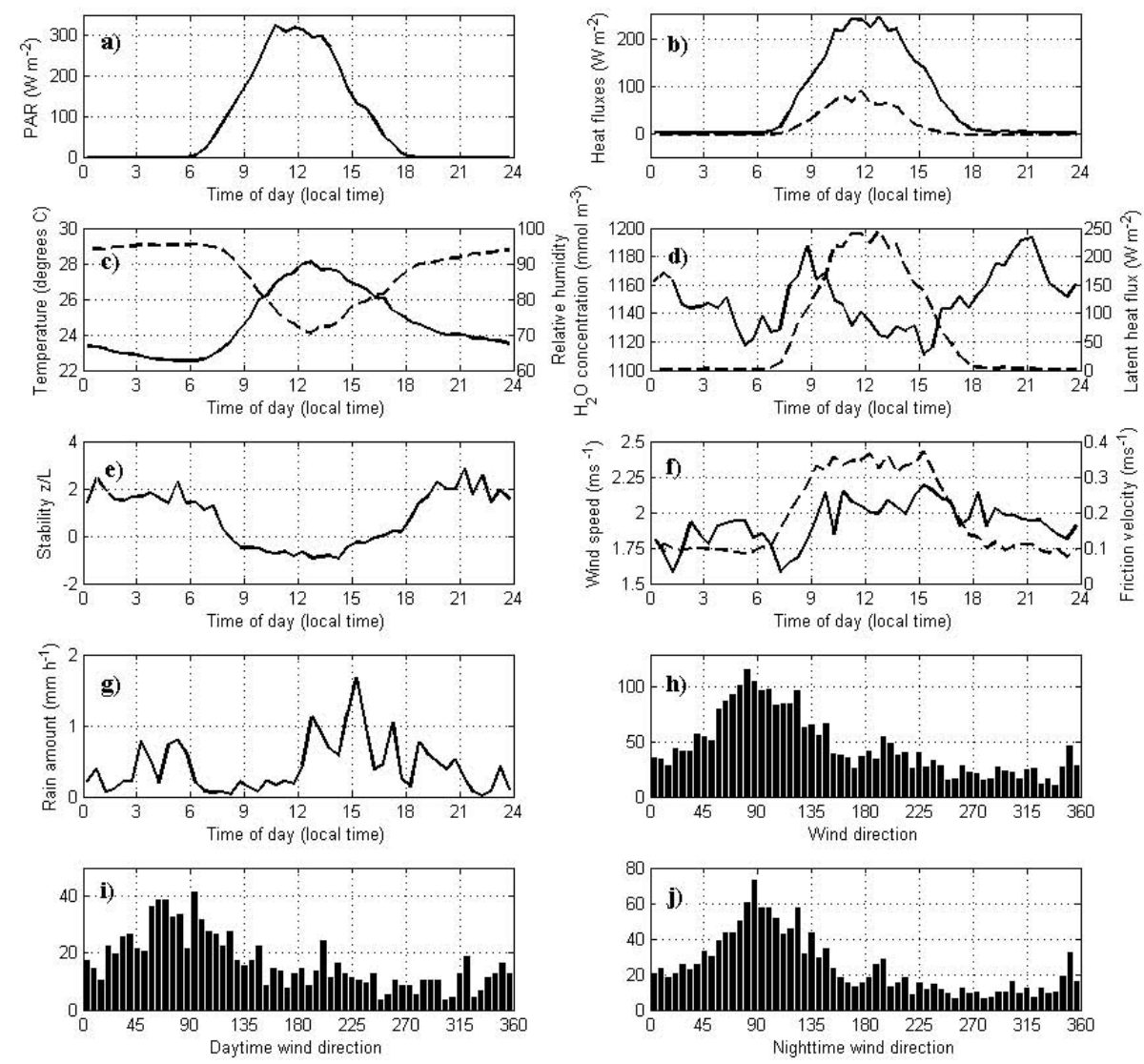

Fig. 5. Meteorological parameters measured at the top of the K34 tower. (a) Photosynthetic active radiation (PAR), (b) latent heat flux (solid) and sensible heat flux (dashed), (c) temperature (solid) and relative humidity (dashed), (d) water vapor concentration (solid) and latent heat flux (dashed), (e) z/L (altitude of measurements divided by the Obukhov length), (f) horizontal wind speed (solid) and friction velocity (dashed) and (g) rain amount, (h) wind direction distribution, (i) daytime (09:00-17:00) wind direction distribution and (j) nighttime (20:00-07:00) wind direction distribution.

sector. Between $330^{\circ}$ and $360^{\circ}$ the fluxes are upward and relatively large in magnitude in comparison to other wind directions. Winds from this sector likely transports air from the vicinity of the diesel generator.

Mass concentration of equivalent black carbon $\left(\mathrm{BC}_{\mathrm{e}}\right)$ was used as a measure of the degree of anthropogenic influence during the campaign. While it has been shown that biogenic organic compounds contribute as much as $50 \%$ to the light absorption by the wet season Amazon aerosol (Artaxo et al., 1988; Guyon et al., 2004), it is likely that this influence is weaker at the MAAP wavelength of $670 \mathrm{~nm}$ than at the wavelength of $565 \mathrm{~nm}$ used by Guyon et al. (2004). This suggests that $\mathrm{BC}_{\mathrm{e}}$ is a valid tracer for anthropogenic combustion influences, at least at concentrations above the background level of about $50 \mathrm{ng} \mathrm{m}^{-3}$.

Figure 7 shows how the total aerosol number concentration at $\mathrm{K} 34$ compares to $\mathrm{BC}_{\mathrm{e}}$ mass concentration, measured in the container, both like a scatter plot (a) and binned in different $\mathrm{BC}_{\mathrm{e}}$ concentration intervals (b). The aerosol number concentration increases with increasing $\mathrm{BC}_{\mathrm{e}}$ when the
$\mathrm{BC}_{\mathrm{e}}$ concentration is high, roughly for $\mathrm{BC}_{\mathrm{e}}$ concentrations over $80 \mathrm{ng} \mathrm{m}^{-3}$. However, for lower $\mathrm{BC}_{\mathrm{e}}$ concentrations, the aerosol number concentration is more or less constant with increasing $\mathrm{BC}_{\mathrm{e}}$ (Fig. 7b). Thus, it seems that anthropogenic particles dominate the aerosol number population when concentrations are high but have a much lower impact when concentrations are low.

Since this study focuses on the interactions between rain forest and atmosphere during conditions not perturbed by anthropogenic sources, data with high anthropogenic influence have been excluded from the data set. All half-hourly averages of aerosol fluxes and concentrations measured when the average wind direction was between $310^{\circ}$ and $20^{\circ}$ have been completely rejected in order to avoid influence from the diesel generator. Additionally, half hours with $\mathrm{BC}_{\mathrm{e}}$ concentration above $80 \mathrm{ng} \mathrm{m}^{-3}$ or aerosol number concentration above $60 \mathrm{~cm}^{-3}$ have been excluded. Moreover, a few days clearly influenced by inflow of mineral dust with significantly higher concentrations of the trace elements $\mathrm{Al}, \mathrm{Fe}$ and Mn have been rejected. These episodes are likely linked to 

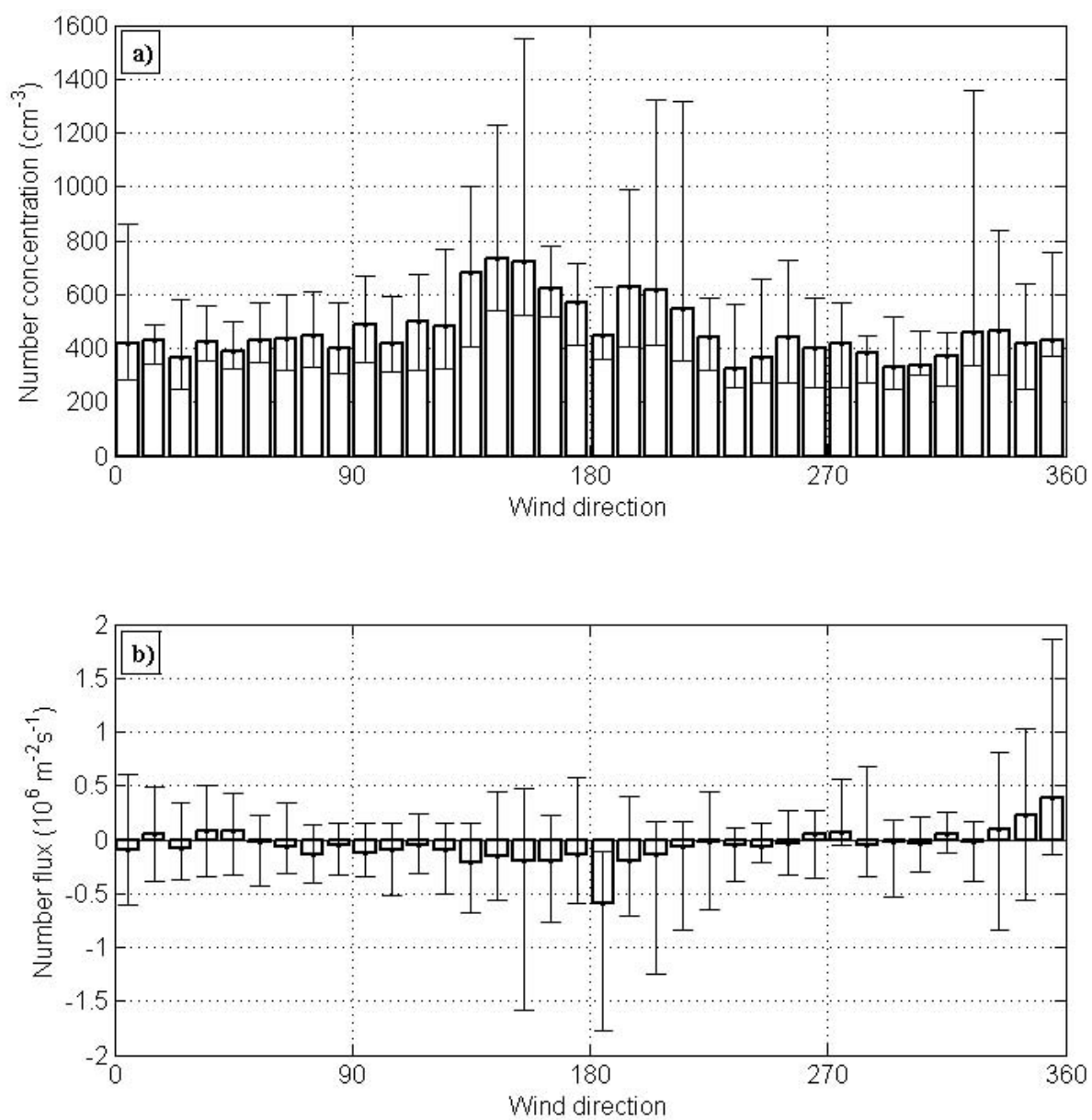

Fig. 6. Aerosol number concentration (a) and aerosol number flux (b) as a function of wind direction. Bars are median values and error bars are 25 and 75 percentiles.
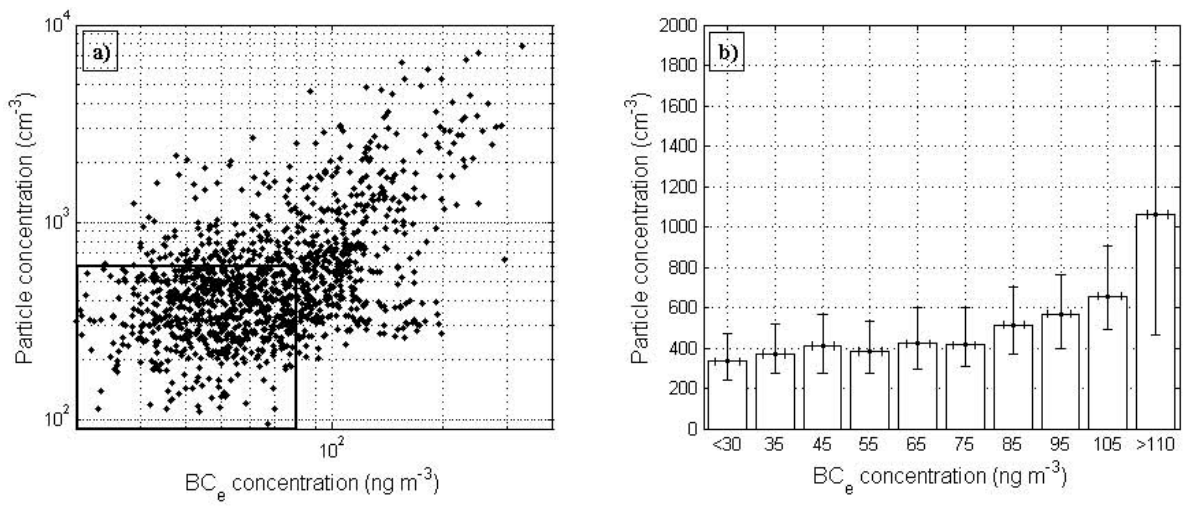

Fig. 7. Relations between total aerosol number concentration at $\mathrm{K} 34$ and mass concentration of $\mathrm{BC}_{\mathrm{e}}$ measured by MAAP instrument in the container presented as (a) scatter plot, (b) Binned black carbon concentrations. Dots inside the rectangle in (a) are half hourly averages obtained during LAM conditions. Bars in (b) represent medians and error bars in both the horizontal and vertical represent 25 and 75 percentiles. All bins represent at least 54 half hours of data. 


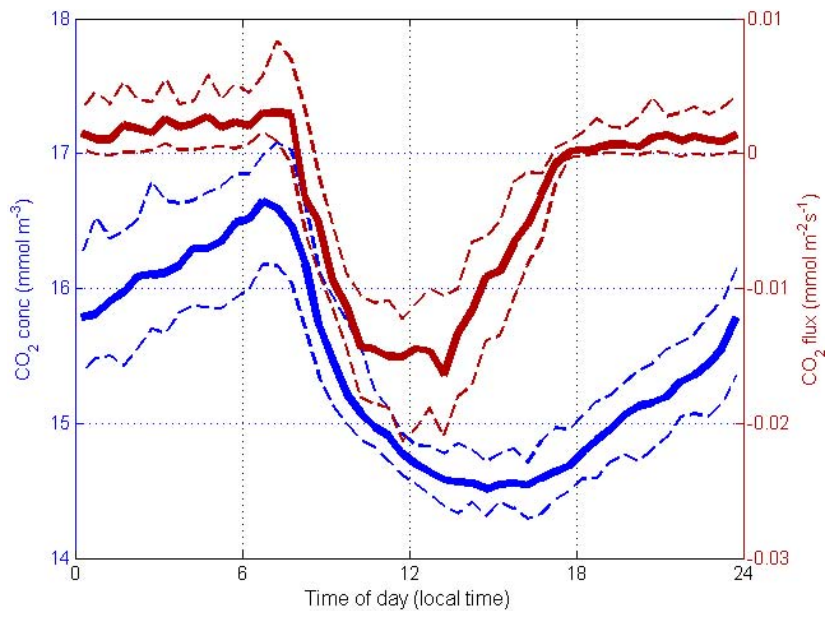

Fig. 8. Median diurnal cycles of $\mathrm{CO}_{2}$ concentration (blue) and vertical flux (red). Solid lines are medians and dashed lines are 25 and 75 percentiles. Each median in the $\mathrm{CO}_{2}$ cycles represents at least 68 values.

transport of Saharan dust to the site (Swap et al., 1992). Finally, half hours when rainfall occurred have been excluded to simplify interpretation. At the end, $47 \%$ of the all halfhourly averaged data fulfilled the criteria for clean conditions and these data will from now on be referred to as LAM (Low Influence of Anthropogenic sources and Mineral dust) conditions.

Local pollution from the diesel generator or the house can be expected to have a larger influence on the $\mathrm{BC}_{\mathrm{e}}$ concentration at the container than on the particle concentration at $\mathrm{K} 34,2 \mathrm{~km}$ away. Therefore, filtering out particle data in K34 due to high $\mathrm{BC}_{\mathrm{e}}$ concentration at the container unfortunately results in a loss of some data that were actually not influenced by anthropogenic sources. Anthropogenic particles transported from Manaus or even further away can be expected to have approximately the same impact on the measurements at the container as at K34.

The filtering process described in this section also has the effect of strongly reducing the aerosol number concentration variability. This is important since stationary conditions are necessary when making flux measurements with the eddy covariance method.

\subsection{Diurnal cycles of concentration and flux of $\mathrm{CO}_{2}$}

The $\mathrm{CO}_{2}$ concentration and flux have very distinct diurnal cycles (Fig. 8). In daytime there is an uptake of $\mathrm{CO}_{2}$ by the forest (downward fluxes) and the atmospheric $\mathrm{CO}_{2}$ concentration consequently decreases. During evening and nighttime, when there is no photosynthetic active radiation and only $\mathrm{CO}_{2}$ emission (upward fluxes), instead the $\mathrm{CO}_{2}$ concentration increases. The percentiles in Fig. 8 reveal that the day to day variability is low in both concentration and flux.
It is also obvious that concentration and flux change in a systematic way from hour to hour.

When studying Fig. 8, it is important to remember that nocturnal respiration fluxes are often underestimated by the eddy covariance method. This underestimation is most significant in calm and clear nights with stable stratification (Goulden et al., 1996, 2006). There is growing evidence that nighttime advection caused by drainage flows is the root cause of the failure to capture the respiration flux in stable conditions at nighttime (Finnigan et al., 2008). Araújo et al. (2008) investigated the nocturnal $\mathrm{CO}_{2}$ concentration field in the heterogenous terrain of the Cuieiras Reserve of valleys and slopes and found that, particularly during stable nights, large amounts of $\mathrm{CO}_{2}$ were transported downslope by drainage flows from the $\mathrm{K} 34$ plateau and being accumulated in valleys.

\subsection{Diurnal cycles of concentration and flux of particles}

Fig. 9 shows diurnal cycles of aerosol number concentration and flux for particles $\left(D_{p}>10 \mathrm{~nm}\right)$. A comparison of the diurnal cycles of aerosol particle concentration and flux in Fig. 9a with the corresponding $\mathrm{CO}_{2}$ cycles in Fig. 8 reveals that the day to day variability in concentration and flux is much larger for particles than for $\mathrm{CO}_{2}$. Figure $9 \mathrm{~b}$ and $\mathrm{c}$ show that the median counting errors for particle concentration and flux are small in relation to the natural variability seen in Fig. 9a. There are of course other sources of uncertainty in aerosol flux quantification than the counting error but these are more difficult to quantify.

Care needs to be taken when analyzing the diurnal cycles of particle number concentration and flux because of the large diurnal variability of these parameters. However, some patterns are clear in Fig. 9a. The aerosol fluxes are close to zero at nighttime but larger in magnitude during daytime when conditions are more turbulent. The force behind this repeating pattern is the dynamics of the convective boundary layer driven by solar radiation. On average the fluxes are clearly downward (negative), which means that the dry deposition sink most of the time dominates over the aerosol emission from the rain forest. It is important to keep in mind that this is valid for the total aerosol number flux. The picture might differ for size segregated aerosol fluxes, which will be the subject of following studies.

During late night and early morning, approximately from 04:00 to around 07:00 LT, the number concentration decreases while particle fluxes are small (Fig. 9a). A small deposition flux, however, can have a relatively large influence on the local number concentration since the nocturnal boundary layer is very shallow. Another factor that may affect the particle concentration during this time period is rainfall. Apart from the precipitation maximum during the afternoon, there is a second maximum between 03:00 and 06:00 LT (Fig. 5g). Even though half hour aerosol data collected during rainfall have been excluded from the data set, 

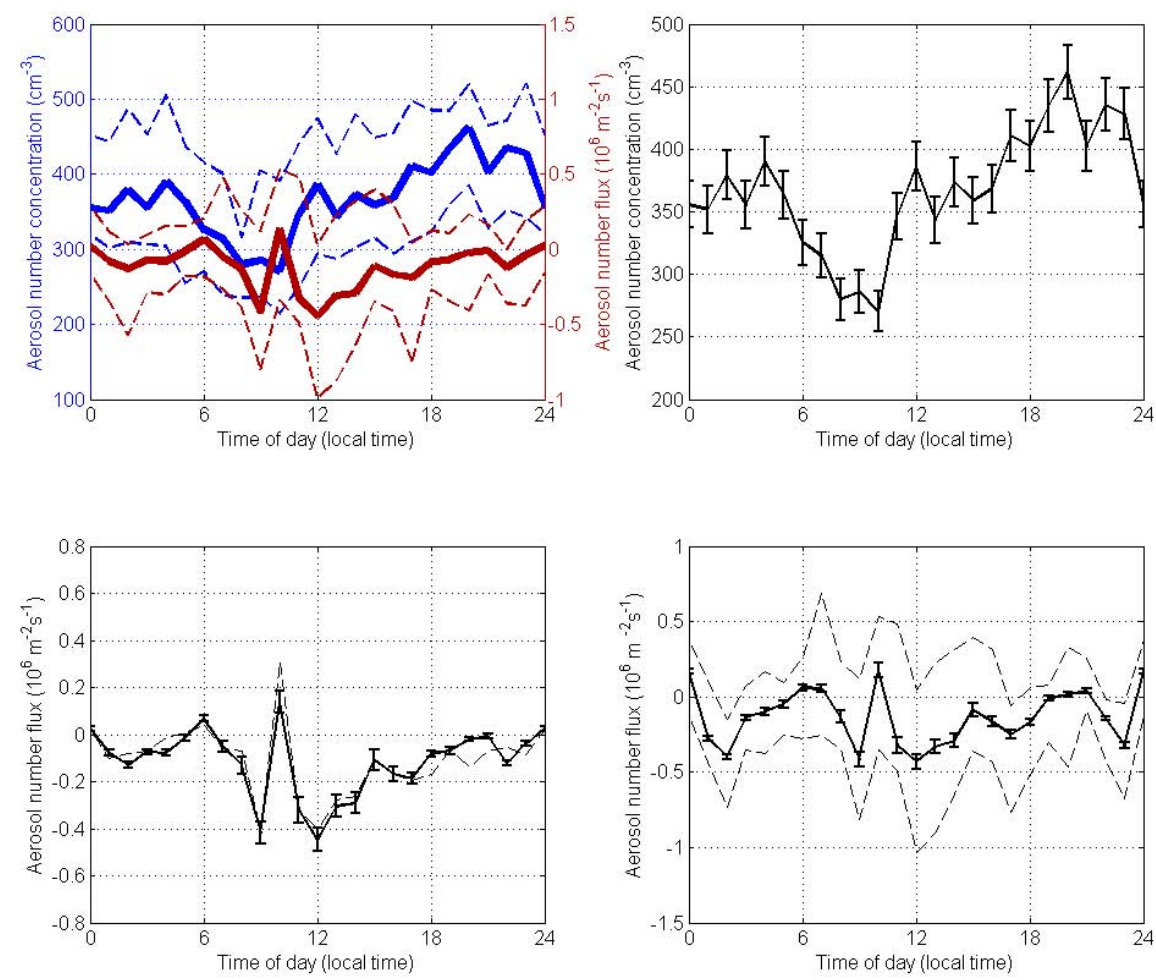

Fig. 9. (a) Median diurnal cycles of aerosol concentration (blue) and vertical flux (red) during LAM conditions. Solid lines are medians and dashed lines are 25 and 75 percentiles. Each median represents at least 23 values. Solid lines in (b) and (c) are the median diurnal cycles of number concentration (b) and flux (c) from (a) but with median counting errors added as error bars. Dashed line in (c) is the median diurnal flux cycle with time periods not fulfilling LAM conditions included. Solid line in (d) is the median diurnal particle flux cycle when friction velocities $<0.1 \mathrm{~ms}^{-1}$ have been filtered out. Each median represents at least 17 values. Dashed lines are corresponding 25 and 75 percentiles and the error bars represent the median counting errors.

there may still be an impact of the rain on the particle concentration, since particle data collected after the rainfall remains in the dataset.

Around 10:00 LT in the morning there is a peak in upward flux (Fig. 9a). This is the just after the nocturnal stable boundary layer is defeated according to the discussion in Sect. 3.2. This upward flux peak is most likely an effect of boundary layer dynamics rather than particle emission which will be discussed in more detail in Sect. 3.5. Even if the upward flux would be a result of primary aerosol emission, it would have a very limited impact on the particle concentration. A source active during one hour of $2 \times 10^{5}$ particles $\mathrm{m}^{-2} \mathrm{~s}^{-1}$, like the median upward flux at 10:00 LT in Fig. 9a, would only increase the mixed layer concentration with 3.6 particles per $\mathrm{cm}^{3}$ in a $200 \mathrm{~m}$ thick mixed layer and with 0.7 particles per $\mathrm{cm}^{3}$ in a $1000 \mathrm{~m}$ thick mixed layer.

Between 10:00 and 12:00 LT, the particle concentration makes a jump to a higher concentration, a period when the mixed layer can be expected to grow rapidly by entrainment. It is interesting to compare Fig. 9a (and b) with the diurnal cycle of water vapor (Fig. 5d). In approximately the same time period as the water vapor concentration rapidly drops as a result of entrainment of drier air, the particle concentration increases. The increase in particle concentration, which can be seen both in the median curve and the percentile curves, does not seem to be due to primary aerosol emission since this period is dominated by downward fluxes. Instead it seems that the air that is entrained from the residual layer into the rapidly growing mixed layer increases the mixed layer aerosol number. This increase in number concentration is accompanied by increasing dry deposition seen in the enhanced downward particle fluxes, but this is not enough to counteract the concentration increase. During the afternoon when the mixed layer usually is well developed, the particle number concentration is more stable and the flux is still negative on average. (However, if data obtained during rainfall are included in the cycles in Fig. 9a and b, the particle concentration is on average somewhat reduced during the afternoon, when rain amounts are at maximum, but this reduction is smaller than the increase in concentration between 10:00 and 12:00 LT).

By using the values on the deposition flux during the afternoon in Fig. 9a, it is possible to roughly estimate the impact of the afternoon dry deposition on the number concentration. An average net deposition flux of $\sim 3 \times 10^{5}$ particles $\mathrm{m}^{-2} \mathrm{~s}^{-1}$ 

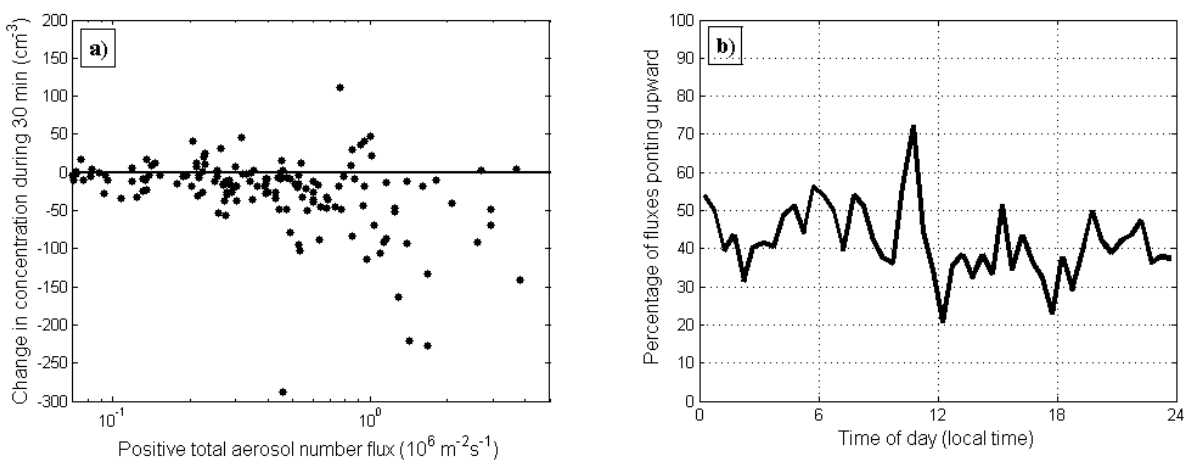

Fig. 10. (a) Daytime (06:00-17:00 LT) half-hourly averaged aerosol fluxes that are positive against change in total aerosol number concentration from half an hour before until the time when the flux was measured. Also data that do not fulfill LAM conditions have been included. However, the wind sector associated with the diesel generator and data collected during rainfall have been excluded. (b) Median diurnal cycle of percentage of upward particle flux. All data used in (b) were collected during LAM conditions.

and a particle concentration of $\sim 370 \mathrm{~cm}^{-3}$ during the afternoon (Fig. 9a), with an assumed mixed layer thickness of $1000 \mathrm{~m}$, will only reduce the particle concentration with approximately $0.3 \%$ per hour.

The particle concentration is at maximum during the evening. Zhou et al. (2002) investigated the aerosol size distribution from March to April (wet season) at a ground station located $125 \mathrm{~km}$ northeast of Manaus. They found that an Aitken and an accumulation mode were present most of the time. An ultrafine mode was present at only $18 \%$ of the cases and could almost exclusively be linked to local anthropogenic pollution. Hence, it seems unlikely that the elevated number concentration during the evening in this study is a result of new particle formation. The particle fluxes point downward so neither primary aerosol emission can explain the rising concentration in the evening. One possible explanation is horizontal transport of particles. Since the wind sector including the diesel generator and the house have been excluded from the data set it is not likely that it is local pollution. The dominating easterly winds advect air from the road between Manaus and Venezuela located $19 \mathrm{~km}$ from the Cueiras Reserve. An ongoing transport of anthropogenic particles that have a negligible influence on the number concentration in daytime when the convective boundary layer is well developed could suddenly have a larger influence once the shallow nocturnal stable boundary layer has formed. The number concentration was often observed to raise rapidly around 18:00 LT when a nocturnal boundary layer usually formed. Hence, anthropogenic sources still might have some influence on the data even after the filtering process described in Sect. 3.2 to LAM conditions.

Figure 9d shows the median diurnal cycle of the particle flux when data collected when the friction velocity is below $0.1 \mathrm{~ms}^{-1}$ have been filtered out. This filtering primarily affects the nighttime fluxes in the median cycle, since the daytime friction velocity most of the time is higher than $0.1 \mathrm{~ms}^{-1}$ (Fig. 5f). Rejecting low-turbulence data will result in an overestimation of the average magnitude of the flux es- pecially in the night, but reduce the uncertainty in the sign of the flux. From Fig. 9d it is clear that the net particle flux points downward at nighttime also when friction velocities below $0.1 \mathrm{~ms}^{-1}$ have been ignored. Even though uncertainties in the particle flux are larger at nighttime, the problem with advection caused by drainage flows (Sect. 3.4) is probably less critical for particles than for $\mathrm{CO}_{2}$. The nocturnal $\mathrm{CO}_{2}$ flux points upward (Fig. 8) and is therefore largely affected by drainage flows within the canopy layer. However, the nocturnal particle flux points downward (Fig. 9) and since the flux is measured above the canopy, it is likely less affected by drainage flows.

\subsection{Upward particle fluxes}

Even though downward aerosol fluxes clearly dominate the diurnal cycle (Fig. 9), there are regularly repeating occasions of positive peaks of aerosol flux. Actually, $40 \%$ of the particle fluxes measured during LAM conditions points upward ( $42 \%$ if including periods when LAM conditions are not fulfilled). When filtering out data collected when the friction velocity is below $0.1 \mathrm{~ms}^{-1}$, the fraction of upward flux is $39 \%$, and when filtering out friction velocities below $0.2 \mathrm{~ms}^{-1}$, the fraction is $37 \%$. The fact that the fractions do not change much when reducing the uncertainty of the sign of the flux by ignoring low turbulence data, makes the obtained percentages of upward flux seem reliable. However, the fact that a certain number of all averaged fluxes are positive does not necessarily mean that there is an emission of particles. A fraction of the obtained fluxes would point upward even if there was no emission because of random uncertainties or stochastic effects (Gaman et al., 2004). Furthermore, entrainment of cleaner air from above can modify the vertical aerosol gradient in a similar way to an emitting source below and thereby produce upward fluxes that are not related to emission (Nilsson et al., 2001b).

Rannik et al. (2003) found $32 \%$ of the fluxes to be pointed upward over a boreal forest in Hyytiälä in Finland. Pryor et 
al. (2008) found more than $40 \%$ of the fluxes to be upward at Hyytiälä and also over a beach forest at Sorø in Denmark. Hence, the upward fractions of particle fluxes measured over a boreal forest seem to be very similar to the fraction of upward fluxes obtained in this study over a tropical rain forest. The observed upward fluxes in the studies by Rannik et al. (2003) and Pryor et al. (2008) were explained by random flux errors, horizontal advection of particles and dilution through entrainment.

Figure 10a shows how the positive fluxes obtained during daytime are related to the change in total number concentration from half an hour before to the time when the flux is measured. Also time periods that do not fulfill LAM conditions have been included in this figure, since it is of interest here to see what happens with the flux also when there are large trends in the particle concentration. It is clear that most of the positive fluxes in Fig. 10a are associated with a decrease in concentration which indicates that these upward fluxes might be linked to entrainment of cleaner air from above. The fact that the highest percentage of upward particle fluxes occurs in the morning (Fig. 10b) during mixed layer growth further supports this hypothesis.

This might seem like a contradiction to the discussion of Fig. 9 where it was suggested that entrainment enriches the mixed layer on particles during mixed layer growth. However, Fig. 9 shows the average cycles and the variability in these cycles is large because different days can show very different behavior concerning these parameters and includes aerosol fluxes in both directions. The entrainment process seems to increase the mixed layer on particles on average. However, if the particle number concentration in the mixed layer is enhanced by some process, the entrainment process can shift from having an enriching effect to instead having a diluting effect on the mixed layer particle concentration. The impact of entrainment on the mixed layer particle concentration of course also depends on the particle concentration in the residual layer.

Figure 11 shows two examples where the entrainment process seems to have opposite effects on the mixed layer particle numbers. Both these days were free from rainfall. The curves referring to 21 March (a) somewhat reminds of the average diurnal cycles in Fig. 9. The aerosol number concentration decreases at nighttime. In the morning, around 09:00 LT, there is a rapid increase in particle concentration, most likely due to entrainment of air with higher concentration into the growing mixed layer. The curves for particle concentration and flux during 24 March show a different behavior. The particle concentration at nighttime is higher than the nighttime concentration on 21 March. When the mixed layer growth starts in the morning of 24 March, the concentration instead drops to a much lower concentration. Hence, the entrainment seems here to have a diluting effect on the mixed layer particle concentration. A quite large upward flux appears around 10:00 LT just when the concentration starts decreasing. This upward flux is most likely a result of a modified vertical par-

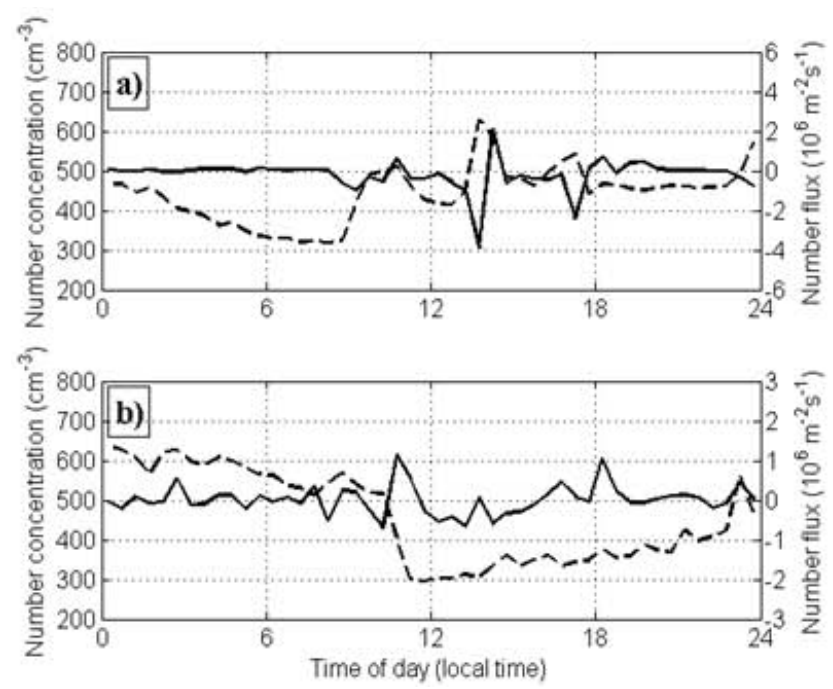

Fig. 11. Aerosol number concentration (dashed line) and flux (solid line) during 21 March (a) and 24 March (b).

ticle gradient as a result of entrainment of cleaner air from aloft into a rapidly growing mixed layer after the nocturnal inversion has been defeated.

Thus, from Fig. 10 and Fig. 11 it seems that entrainment of cleaner air from above can explain a high fraction of the upward fluxes even though entrainment on average seems to be a process that enriches the mixed layer on particles. The upward flux peak at 10:00 LT (Fig. 9a) seems to occur those days when entrainment has a diluting impact on the mixed layer. The fact that the peak in upward flux around 10:00 LT becomes even larger in magnitude when also data that not fulfill the LAM conditions are included (dashed line in Fig. 9c) further strengthens the hypothesis that this peak is not particle emission from the rain forest. If the peak was due to particle emission, one could expect the magnitude of the upward flux to be lower when background concentrations are high, since the deposition flux would then be larger and mask a larger fraction of the emission. If the peak was due to entrainment of cleaner air, on the other hand, one would expect the peak to be larger when the surface layer is polluted which agrees with Fig. 9c.

\subsection{Particle transfer velocities}

The particle dry deposition velocity can be estimated from flux measurements by dividing the particle flux with the number concentration. Since measured fluxes may be either positive or negative, the term transfer velocity is preferable over the widely used term "deposition velocity" (Held et al., 2006). The transfer velocity $v_{t}$ is defined as

$v_{t}=-\frac{F}{c}$ 


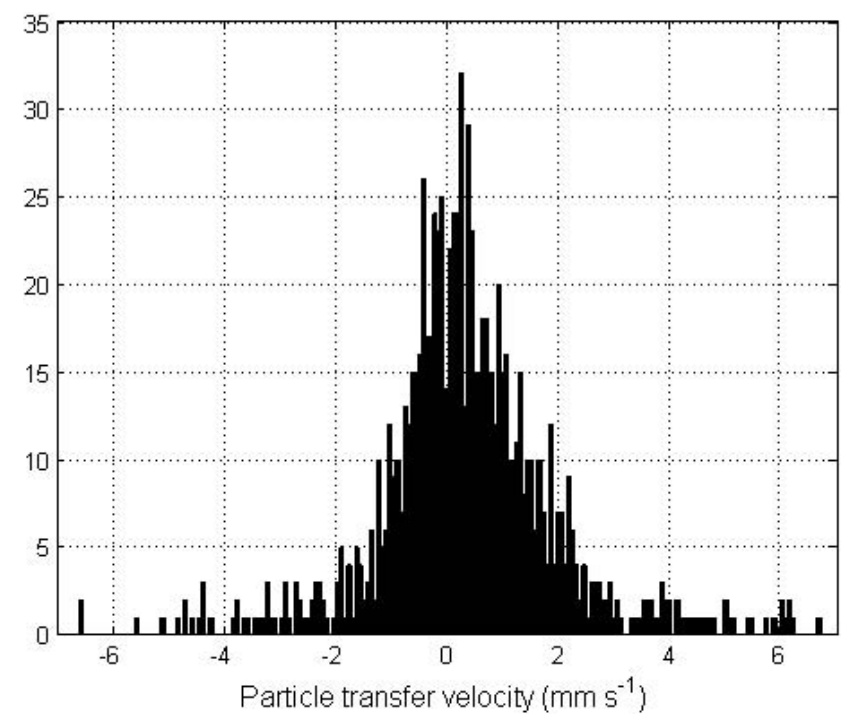

Fig. 12. Distribution of particle transfer velocities obtained in LAM conditions.

where $F$ is the particle number flux and $c$ is the particle number concentration. Positive values on $v_{t}$ represents net downward flux.

Figure 12 shows how the transfer velocities are distributed in this study. Positive values (deposition) dominate. In this study, $90 \%$ of the transfer velocities during LAM conditions were lower than $2.2 \mathrm{~mm} \mathrm{~s}^{-1}$. Buzorius et al. (2000) reported particle transfer velocities over a Scots pine forest between 1 and $40 \mathrm{~mm} \mathrm{~s}^{-1}$ with the highest velocities associated with new particle formation events due to more efficient Brownian diffusion of ultrafine particles. Particle size has a large influence on the transfer velocity. Since the aerosol size distribution in the Amazon during the wet season is dominated by an Aitken and an accumulation mode (Zhou et al., 2002), it is logical that the transfer velocities in this study are in the lower range of the transfer velocity interval reported by Buzorius et al. (2000). Another reason for the low particle deposition velocities obtained in this study is the low wind speeds, which only reach slightly above $2 \mathrm{~ms}^{-1}$ on average during daytime (Fig. 5f).

Figure 13 shows how the transfer velocity depends on the friction velocity in this study. A linearly curve has been fitted to the median values of the transfer velocity in the different friction velocity $\left(u_{*}\right)$ intervals (Fig. 13b). The relation is described by

$v_{t}=2.4 \times 10^{-3} \times u_{*}\left[\mathrm{~ms}^{-1}\right]$

with the correlation coefficient 0.88 . Both positive and negative transfer velocities were included in the calculations of the median transfer velocities in Fig. 13. This means that the median transfer velocities are somewhat underestimated if considering them as deposition velocities, since some of the upward fluxes are pointing upward for a physical rea- son and not only as a result of stochastic or random errors. However, to exclude all negative transfer velocities (upward fluxes) would probably result in an even larger overestimation of the deposition velocity, since a large fraction of the negative transfer velocities are only results of stochastic or random errors.

Gaman et al. (2004) also found a linear relation between particle deposition velocity and friction velocity when they measured fluxes of $50 \mathrm{~nm}$ particles over a Scots pine forest. Their relation is given by

$v_{t}=1.2 \times 10^{-2} \times u_{*}\left[\mathrm{~ms}^{-1}\right]$

One important reason for the higher slope in their relation in comparison with the slope in Eq. (8) is most likely the efficient Brownian diffusion of $50 \mathrm{~nm}$ particles.

\subsection{Origin of the depositing particles}

The diurnal cycles of particle concentrations and fluxes in Fig. 9 indicate that entrainment to a high degree controls the aerosol number population within the mixed layer. On average, an enhancement in concentration is seen when the mixed layer grows and a decrease in concentration is seen during nighttime when the nocturnal stable boundary layer is often decoupled from the residual layer above. The particle fluxes are mostly pointing downward which indicates that the number source of primary aerosol particles within the footprint of the measurements in this study was small. The fact that time periods with high anthropogenic influence have been excluded from the data set suggests that most of the depositing particles in this study are natural particles. However, the increasing aerosol number concentration during the evening indicates that anthropogenic sources still could play a role after the data filtering process described in Sect. 3.3 to achieve LAM conditions. Therefore, the question arises whether influences of anthropogenic sources might be the reason for a considerable part of the downward particle fluxes, which would open the possibility for that the true magnitude of the primary aerosol emission of natural aerosols could be masked by deposition of anthropogenic particles. An efficient way of investigating this is to analyze what happens with the particle flux in the absolute cleanest conditions, or even better, what happens with the transfer velocity since this parameter is independent of the particle concentration.

Figure 14 shows how particle transfer velocity varies with particle number concentration (a) and $\mathrm{BC}_{\mathrm{e}}$ mass concentration (b). Also data that do not fulfill the conditions of LAM are included here since it is of interest to see how the particle deposition velocities behave also when particle and $\mathrm{BC}_{\mathrm{e}}$ concentrations are higher. The transfer velocity is still defined as pointing downward when it is positive. If the net downward particle flux obtained in this study would only be a result of transport of anthropogenic particles into the forestatmosphere system, the transfer velocity would be expected to become negative (pointing upward) or at least close to zero 

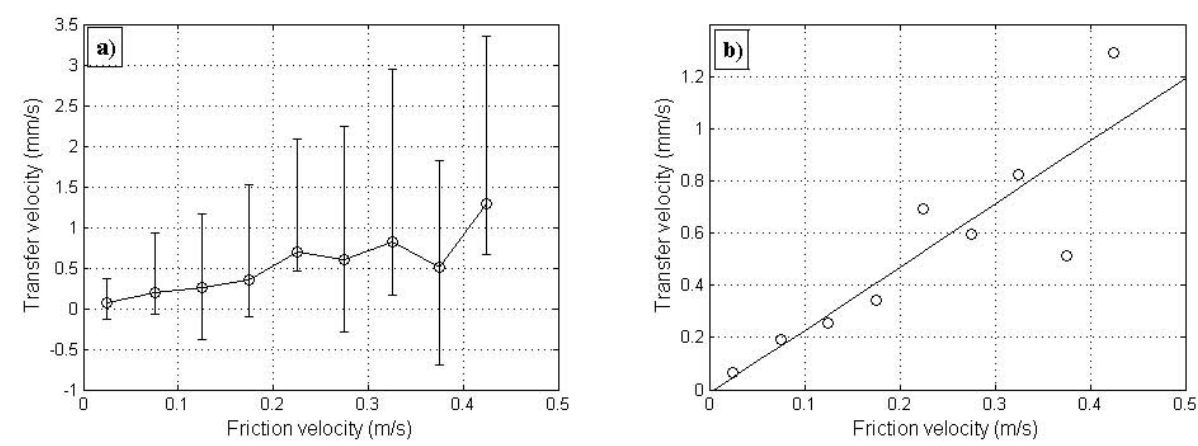

Fig. 13. (a) Medians of the particle transfer velocity over constant friction velocity intervals. The errorbars represent 25 and 75 percentiles. (b) Medians of transfer velocities over constant friction velocities (rings) and a linearly fitted curve (solid line) to the median values. All data were collected during LAM conditions.
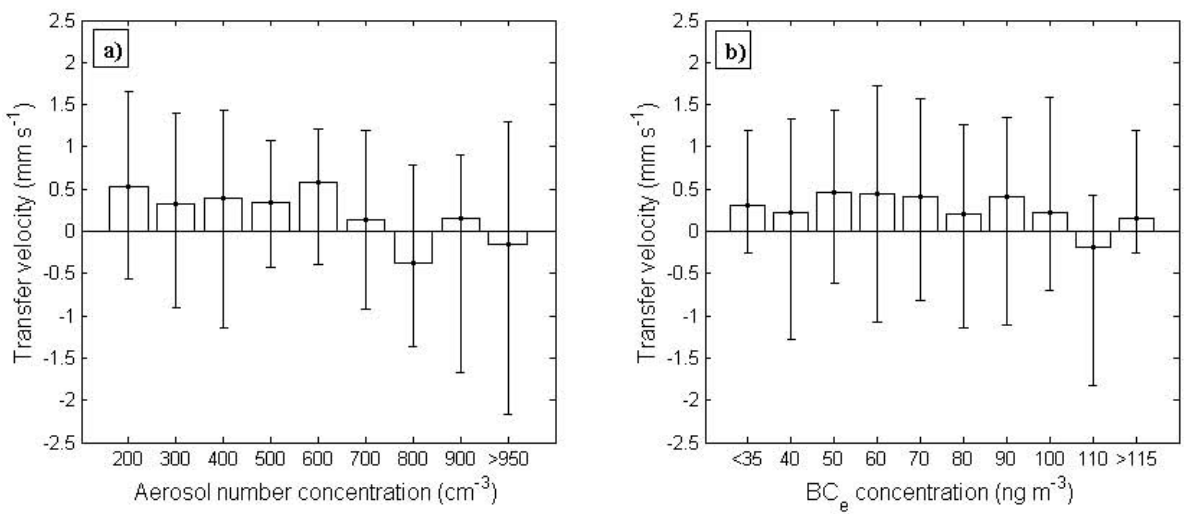

Fig. 14. Daytime medians of particle transfer velocities (bars) and 25 and 75 percentiles (error bars) within different intervals of total aerosol number concentration (a) and $\mathrm{BC}_{\mathrm{e}}$ mass concentration at the container (b). All bins represent medians of at least 50 half hour transfer velocity averages. The wind sector associated with risk of pollution from the diesel generator and data collected during rainfall have been excluded.

in the cleanest conditions. However, the transfer velocity is positive for both the lowest particle concentrations (Fig. 14a) and for the lowest $\mathrm{BC}_{\mathrm{e}}$ concentrations (Fig. 14b) and there is no trend towards more negative or less positive transfer velocities for lower concentrations of particles or $\mathrm{BC}_{\mathrm{e}}$. The only bins that represent negative averages of the transfer velocity are actually found at higher concentrations of particles (a) and of $\mathrm{BC}_{\mathrm{e}}$ (b). These negative transfer velocities are probably a result of entrainment of cleaner air from aloft and/or local pollution events producing upward fluxes.

Hence, even for the absolute cleanest conditions in this study the transfer velocities are on average positive which implies that the net downward particle fluxes cannot be explained only by deposition of anthropogenic particles. Neither can the net deposition flux be explained by deposition of mineral dust, since periods of significantly higher concentrations of trace elements associated with mineral dust have been excluded from the data set. Marine aerosols are known to be transported over the rain forest with trade winds and it represents a major source of sulfur for otherwise sulfur defi- cient rainforest ecosystems (Andreae et al., 1990). However, marine aerosols are dominated by accumulation and coarse mode particles, which will get rapidly activated into cloud droplets and removed by wet scavenging in intensified convection over the land. During the wet season, particles as small as $60-80 \mathrm{~nm}$ are activated into cloud droplets (Roberts et al., 2001; Roberts et al., 2002). Single particle analysis from airborne measurements over north-eastern Amazonia have shown that most of the marine signature is lost within some hundreds of $\mathrm{km}$ from the coast (Krejci et al., 2005a). Then the question remains where the majority of the particles that are deposited over the rain forest in this study originally come from. Even if this cannot directly be proved from the results of this study, the best guess is probably that the majority of the deposited particles have been formed within the atmosphere, simply because it is hard to explain the net downward aerosol flux by any other particle sources.

However, a reasonable question is whether there may be large horizontal variations in primary aerosol emission over the Amazon rain forest. If this is the case, a fraction of 
the deposited particles in this study could actually be primary aerosol particles emitted from other areas of the Amazon where primary aerosol emission is more favored. However, there are indications that the Amazon rain forest is a rather homogeneous entity with respect to aerosol sources and sinks. Previous observations of aerosol number concentrations and size distributions (e.g. Guyon et al., 2003; Krejci et al., 2003; Rissler et al., 2004; Roberts et al., 2001; Zhou et al., 2002) show very stable aerosol number densities and aerosol size distributions with very low variability in space and time during the wet season. This is a rather strong argument for horizontal homogeneity concerning rain forest properties with respect to sources and sinks of aerosol particles. However, aerosol flux measurements need to be repeated in other areas of the Amazon before any final conclusions may be drawn of the importance of primary aerosol emission as a number source in the Amazon rain forest.

\section{Summary and conclusions}

Aerosol number flux and $\mathrm{CO}_{2}$ flux measurements were measured with the eddy covariance method over the Amazon rain forest during the wet season in 2008. The measurements were performed at the top of the K34 flux tower in the Cuieiras Reserve, Manaus, Brazil. The main objective was to examine if sinks or sources dominate the aerosol number fluxes and under what conditions. Here the key results and main conclusions are presented.

- The day to day variability of fluxes at K34 was much larger for particles than for $\mathrm{CO}_{2}$.

- The net particle number flux on average pointed downward which means that the number source of primary aerosol particles within the footprint of K34 was small. It can however not be excluded that there are occasional episodes of true particle emissions. It is also important to remember that the CPC total number count is dominated by the sizes where most particles are found. This means that emissions of larger particles, which are low in number but may be large in terms of mass, drown in the number deposition flux.

- About $40 \%$ of the half-hourly averaged particle fluxes in this study pointed upward which is a similar fraction to what has been observed over boreal forests.

- The upward particle fluxes in this study frequently appeared in the morning hours and were often accompanied by a decrease in number concentration which indicates that the upward fluxes to a large extent may be linked to entrainment fluxes and not to primary aerosol emission.

- Particle transfer velocities at K34 increase with increasing friction velocity and a curve fitted to the data is described by the relation $v_{t}=2.4 \times 10^{-3} \times u_{*}\left[\mathrm{~ms}^{-1}\right]$. In this study, $90 \%$ of the transfer velocities were lower than $2.2 \mathrm{~mm} \mathrm{~s}^{-1}$.

Hence, in this study it was shown that in terms of aerosol numbers, particle fluxes on average pointed downward at the tower K34 in the Amazon rain forest during the wet season. The fact that the particle flux pointed downward even in the absolute cleanest conditions indicates that the contribution of primary biogenic aerosol particles to the aerosol population in the Amazon boundary layer may be low in terms of number concentrations. However, the possibility of horizontal variations in primary aerosol emission from the Amazon rain forest cannot be ruled out. A fraction of the depositing particles could possibly be primary aerosol particles emitted from the rain forest somewhere outside the footprint. Therefore, aerosol flux measurements need to be repeated in other areas of the Amazon before any final conclusions may be drawn of the importance of primary aerosol emission as a particle number source in the Amazon rain forest.

Acknowledgements. This study was carried out in close cooperation with São Paulo University and within the framework of the LBA project. We would like to thank the National Institute for Research in the Amazon (INPA) and the LBA infrastructure team for all help and support during this campaign. Paulo Artaxo acknowledges financial support from the CNPq/MCT Millennium Institute Program and FAPESP. We thank Paulo Henrique Oliveira (in memoriam) for support during the whole sampling campaign.

Swedish participation was provided by Swedish International Development Cooperation Agency (Sida/SAREC), the Swedish Research Council (VR) and from the 50th birthday of King Carl XVI Gustav Foundation for Science Technology and Environment. We also acknowledge Leif Bäcklin and Kai Rosman for technical assistance and Johan Ström, Thomas Kristensen, Thorsten Mauritzen and Meinrat $\mathrm{O}$. Andreae for good discussions.

Edited by: R. Cohen

\section{References}

Andreae, M. O., Berresheim, H., Bingemer, H., Jacob, D. J., Lewis, B. L., Li, S. M., and Talbot, R. W.: The atmospheric sulfur cycle over the Amazon basin. 2. Wet season, J. Geophys. Res., 95, 16813-16824, 1990.

Andreae, M. O. and Crutzen, P. J.: Atmospheric aerosols: Biogeochemical sources and role in atmospheric chemistry, Science, 276, 1052-1058, 1997.

Andreae, M. O., Artaxo, P., Brandao, C., Carswell, F. E., Ciccioli, P., da Costa, A. L., Culf, A. D., Esteves, J. L., Gash, J. H. C., Grace, J., Kabat, P., Lelieveld, J., Malhi, Y., Manzi, A. O., Meixner, F. X., Nobre, A. D., Nobre, C., Ruivo, M. D. L. P., Silva-Dias, M. A., Stefani, P., Valentini, R., von Jouanne, J., and Waterloo, M. J.: Biogeochemical cycling of carbon, water, energy, trace gases, and aerosols in Amazonia: The LBAEUSTACH experiments, J. Geophys. Res., 107(D20), 8066 , doi:10.1029/2001JD000524, 2002. 
Andreae, M. O., Rosenfeld, D., Artaxo, P., Costa, A. A., Frank, G. P., Longo, K. M., and Silva-Dias, M. A. F.: Smoking rain clouds over the Amazon, Science, 303(5662), 1337-1342, 2004.

Andreae, M. O. and Gelencsér, A.: Black carbon or brown carbon? The nature of light-absorbing carbonaceous aerosols, Atmos. Chem. Phys., 6, 3131-3148, 2006,

http://www.atmos-chem-phys.net/6/3131/2006/.

Andreae, M. O.: Correlation between cloud condensation nuclei concentration and aerosol optical thickness in remote and polluted regions, Atmos. Chem. Phys., 9, 543-556, 2009,

http://www.atmos-chem-phys.net/9/543/2009/.

Araujo, A. C., Nobre, A. D., Kruijt, B., Elbers, J. A., Dallarosa, R.,Stefani, P., von Randow, C., Manzi, A. O., Culf, A. D., Gash, J. H. C., Valentini, R., and Kabat, P.: Comparative measurements of carbon dioxide fluxes from two nearby towers in a central Amazonian rainforest: The Manaus LBA site, J. Geophys. Res., 107(D20), 8090, doi:10.1029/2001JD000676, 2002.

Araújo, A. C., Kruijt, B., Nobre, A. D., Dolman, A. J., Maarten, J. W., Moors, E.J., and Souza, J. S.: Nocturnal accumulation of $\mathrm{CO}_{2}$ underneath a tropical forest canopy along a topographical gradient, Ecol. Appl., 18(6), 1406-1419, 2008.

Artaxo, P., Storms, H., Bruynseels, F., Grieken, R. V., and Maenhaut, W.: Composition and sources of aerosols from the Amazon basin, J. Geophys. Res., 93, 1605-1615, 1988.

Artaxo, P., Maenhaut, W., Storms, H., and Van Grieken, R.: Aerosol characteristics and sources for the Amazon basin during the wet season, J. Geophys. Res., 95(D10), 16971-16985, 1990.

Artaxo, P., Gerab, F., Yamasoe, M. A., and Martins, J. V.: Fine Mode Aerosol Composition in Three Long Term Atmospheric Monitoring Sampling Stations in the Amazon Basin, J. Geophys. Res., 99(D11), 22857-22868, 1994.

Artaxo, P. and Hansson H. C.: Size distribution of biogenic aerosolparticles from the Amazon Basin, Atmos. Environ., 29, 393-402, 1995.

Betts, A. K., Gatti, L., Silva Dias, M. A., and Fuentes, J. D.: Surface diurnal cycle and boundary layer structure over Rondõnia during the rainy season, J. Geophys. Res., 107(D20), 8065, doi:10.1029/2001JD000356, 2002.

Buzorius, G., Rannik, Ü, Mäkelä, J. M., Keronen, P., Vesala, T., and Kulmala, M.: Vertical aerosol fluxes measured by the eddy covariance method and deposition of nucleation mode particles above a Scots pine forest in southern Finland, J. Geophys. Res., 105, 19905-19916, 2000

Buzorius, G., Rannik, Ü., Nilsson E. D., and Kulmala, M.: Vertical fluxes and micrometeorology during the new aerosol particle formation, Tellus, 53B, 394-405, 2001.

Buzorius, G., Rannik, Ü., Nilsson, E. D., Vesala, T., and Kulmala, M.: Analysis of dry deposition velocity measurement techniques for particles smaller than $100 \mathrm{~nm}$, J. Aerosol Sci., 34, 747-764, 2003

Campos, J. G., Acevedo, O. C., Tota, J., and Manzi, A. O.: On the temporal scale of the turbulent exchange of carbon dioxide and energy above a tropical rain forest in Amazonia, J. Geophys. Res., 11(4), D08124, doi:10.1029/2008JD011240, 2009.

Claeys, M., Graham, B., Vas, G., Wang, W., Vermeylen, R., Pashynska, V., Cafmeyer, J., Guyon, P., Andreae, M. O., Artaxo, P., and Maenhaut, W.: Formation of secondary organic aerosols through photo-oxidation of isoprene, Science, 303, 1173-1176, 2004.

Crutzen, P. J. and Andreae, M. O.: Biomass burning in the trop- ics: Impact on atmospheric chemistry and biogeochemical cycles, Science, 250, 16769-16778, 1990.

Davidson, E. A. and Artaxo, P.: Globally significant changes in biological processes of the Amazon Basin: Results of the Largescale Biosphere-Atmosphere Experiment, Global Change Biol., 10(5), 1-11, doi: 10.1111/j.1529-8817.2003.00779.x. 2004.

Doebelin, E. O.: Measurement Systems, McGraw-Hill, New York, USA, 104-194, 1990.

Ekman, A. M. L., Krejci R., Engstrom A., Strom J., de Reus, M., Williams, J. and Andreae, M. O.: Do organics contribute to small particle formation in the Amazonian upper troposphere?, Geophys. Res. Lett., 35, L17810, doi:10.1029/2008GL034970, 2008.

Eltahir, E. A. B. and Bras, R. L.: Precipitation recycling, Rev. Geophys., 34, 367-378, 1996

Finnigan, J., Clement, R., Malhi, Y., Leuning, R., and Cleugh, H. A.: A re-evaluation of long-term flux measurement techniques. Part I. Averaging and coordinate rotation, Bound. Lay. Meteorol., 107, 1-48, 2003.

Finnigan, J.: An introduction to flux measurements in difficult conditions, Ecol. Appl., 18(6), 1340-1350, 2008.

Fisch, G., Tota, J., Machado, L. A. T., Dias, M., Lyra, R. F. D., Nobre, C. A., Dolman, A. J., and Gash, J. H. C.: The convective boundary layer over pasture and forest in Amazonia, Theo. Appl Clim., 78, 47-59, 2004.

Gaman, A., Rannik, Ü., Aalto, P., Pohja, T., Siivola, E., Kulmala, M., and Vesala T.: Relaxed eddy accumulation system for size resolved aerosol flux measurements, J. Atm. Ocean. Tech., 21, 933-943, 2004.

Garstang, M., Ulanski, S., Greco, S., Scala, J., Swap, R., Fitzjarrald, D., Browell, E., Shipman, M., Connors, V., Harriss, R. and Talbot, R.: The Amazon Boundary-Layer Experiment (ABLE 2B): a meteorological perspective, B. Am. Meteor. Soc., 71, 19-31, 1990.

Goulden, M. L., Munger, J. W., Fan, S. M., Daube, B. C., and Wofsy, S. C.: Measurements of carbon sequestration by longterm eddy covariance: Methods and a critical evaluation of accuracy, Global Change Biol., 2, 169-182, 1996.

Goulden, M. L., Miller, S. D., and da Rocha, H. R.: Nocturnal cold air drainage and pooling in a tropical rain forest, J. Geophys. Res., 111, D08S04, doi:10.1029/2005JD006037, 2006.

Graham, B., Guyon, P., Maenhaut, W., Taylor, P. E., Ebert, M., Matthias-Maser, S., Mayol-Bracero, O. L., Godoi, R., Artaxo, P., Meixner, F. X., Moura, M. A., Rocha, C. H., Grieken, R. V., Glovsky, M., Flagan, R., and Andreae, M. O.: Composition and diurnal variability of the natural Amazonian aerosol., J. Geophys. Res., 108(D24), 4765, doi:10.1029/2003JD004049, 2003.

Gunthe, S. S., King, S. M., Rose, D., Chen, Q., Roldin, P., Farmer, D. K., Jimenez, J. L., Artaxo, P., Andreae, M. O., Martin, S. T., and Pschl, U.: Cloud condensation nuclei in pristine tropical rainforest air of Amazonia: size-resolved measurements and modeling of atmospheric aerosol composition and CCN activity, Atmos. Chem. Phys., 9, 7551-7575, 2009, http://www.atmos-chem-phys.net/9/7551/2009/.

Guyon, P., Graham, B., Beck, J., Boucher, O., Gerasopoulos., E., Mayol-Bracero, O. L., Roberts, G. C., Artaxo, P., and Andreae, M. O.: Physical properties and concentration of aerosol particles over the Amazon tropical forest during background and biomass burning conditions, Atmos. Chem. Phys., 3, 951-967, 2003a, http://www.atmos-chem-phys.net/3/951/2003/. 
Guyon, P., Graham, B., Roberts, G. C., Mayol-Bracero, O. L., Maenhaut, W., Artaxo, P., and Andreae, M. O.: In-canopy gradients, composition, sources, and optical properties of aerosol over the Amazon forest, J. Geophys. Res., 108(D18), 4591, doi:10.1029/2003JD003465, 2003b.

Guyon, P., Graham, B., Roberts, G. C., Mayol-Bracero, O. L., Maenhaut, W., Artaxo, P., and Andreae, M. O.: Sources of optically active aerosol particles over the Amazon forest, Atmos. Environ., 38, 1039-1051, 2004.

Held, A., Nowak, A., Wiedensohler, A., and Klemm, O.: Field measurements and size-resolved model simulations of turbulent particle transport to a forest canopy, J. Aerosol Sci., 37, 786-798, 2006.

Kesselmeier, J. and Staudt, M.: Biogenic Volatile Organic Compounds (VOC): An Overview on Emission, Physiology and Ecology, J. Atmos. Chem., 33, 23-88, 1999.

Krejci, R., Ström, J., de Reus, M., Hoor, P., Williams, J., Fischer, H., and Hansson, H. C.: Evolution of aerosol properties over the rain forest in Surinam, South America, observed from aircraft during the LBA-CLAIRE 98 experiment, J. Geophys. Res., 108, 4561, doi:10.1029/2001JD001375, 2003.

Krejci, R., Ström, J., de Reus, M., and Sahle, W.: Single particle analysis of the accumulation mode aerosol over the northeast Amazonian tropical rain forest, Surinam, South America, Atmos. Chem. Phys., 5, 3331-3344, 2005a,

http://www.atmos-chem-phys.net/5/3331/2005/.

Krejci, R., Ström, J., de Reus, M., Williams, J., Fischer, H., Andreae, M. O., and Hansson, H. C.: Spatial and temporal distribution of atmospheric aerosols in the lowermost troposphere over the Amazonian tropical rainforest, Atmos. Chem. Phys., 5, 1527-1543, 2005b, http://www.atmos-chem-phys.net/5/1527/2005/.

Kruijt, B., Malhi, Y., Lloyd, J., Nobre, A. D., Miranda, A. C., Pereira, M. G. P., Culf, A., and Grace, J.: Turbulence above and within two Amazon rainforest canopies, Boundary Layer Meteorol., 94, 297-311, 2000.

$\mathrm{Li}, \mathrm{W}$. and $\mathrm{Fu}, \mathrm{R}$., Transition of the large-scale atmospheric and land surface conditions from dry to wet season over Amazonia as diagnosed by the ECMWF re-analysis, J. Climate, 17, 26372651, 2004.

Martin, C. L., Fitzjarrald, D. R., Garstang, M., Oliveira, A. P., Greco, S., and Browell, E.: Structure and growth of the mixing layer over the Amazonian rain forest, J. Geophys. Res., 93, 1361-1375, 1988.

Martin, S. T., Andreae, M. O., Artaxo, P., Baumgardner, D., Chen, Q., Goldstein, A. H., Guenther, A., Heald, C. L., Mayol-Bracero, O. L., McMurry, P. H., Pauliquevis, T., Pöschl, U., Prather, K. A., Roberts, G. C., Saleska, S. R., Silva Dias, M. A., Spracklen, D. V., Swietlicki, E., and Trebs, I.: Sources and properties of Amazonian aerosol particles, Rev. Geophys., in press, 2009.

McWilliam, A. L., Roberts, J. M., Cabral, O. M. R., Leitao, M. V. B. R., de Costa, A. C. L.,Maitelli, G. T., and Zamparoni, C. A. G. P.: Leaf Area Index and Above Ground Biomass of Terra Firme Rain Forest and Adjacent Clearings in Amazonia, Funct. Ecol., 7, 310-317, 1993.

Mårtensson, E. D., Nilsson, E. D., Buzorius, G., and Johansson, C.: Eddy covariance measurements and parameterization of traffic related particle emissions in an urban environment, Atmos. Chem. Phys., 6, 769-785, 2006, http://www.atmos-chem-phys.net/6/769/2006/.

Nepstad, D., Veríssimo, A., Alencar, A., Nobres, C., Lima, E., Lefebvre, P., Schlesinger, P., Potter, C., Moutinho, P., Mendoza, E., Cochrane, M., and Brooks, V.: Large-scale impoverishment of Amazonian forests by logging and fire, Nature, 398, 505-508, 1999.

Nilsson, E. D., Rannik, Ü., Swietlicki, E., Leck, C., Aalto, P. P., Zhou, J., and Norman, M.: Turbulent Aerosol Fluxes over the Arctic Ocean, part 2, wind driven sources from the sea, J. Geophys. Res., 106, 32139-32154, 2001a.

Nilsson, E. D., Rannik, Ü., Buzorius, G., Kulmala, M., and O'Dowd, C.: Effects of the continental boundary layer evolution, convection, turbulence and entrainment on aerosol formation, Tellus, 53B, 441-461, 2001b.

Oliveira, P. H. F., Artaxo, P., Pires, C., Lucca, S., Procopio, A., Holben, B., Schafer, J., Cardoso, L. F., Wofsy, S. C., and Rocha, H. R.: The effect of biomass burning aerosols and clouds on the $\mathrm{CO}_{2}$ flux in Amazonia, Tellus, 59B, 338-349, 2007.

Prenni, A. J., Petters, M. D., Kreidenweis, S. M., DeMott, P. J., and Ziemann, P. J.: Cloud droplet activation of secondary organic aerosol, J. Geophys. Res., 112, D10223, doi:10.1029/2006JD007963, 2007.

Prenni, A. J., Petters, M. D., Kreidenweis, S. M., Heald, C. L., Martin, S., Artaxo, P., Garland, R. M., Wollny, A. G., and Pöschl, U.: Relative roles of biogenic emissions and Saharan dust as ice nuclei in the Amazon basin, Nature Geosci., 2, 402-405, doi:10.1038/ngeo517, 2009

Pryor, S., Barthelemie, R. J., Sørensen, L. L., Larsen, S. E., Sempreviva, A. M., Grönholm, T., Rannik, Ü., Kulmala, M., and Vesala, T.: Upward fluxes of particles over forests: When, where, why?, Tellus B, 60, 372-380, 2008.

Rannik, Ü., Vesala, T., and Keskinen, R.: On the damping of temperature fluctuations in a circular tube relevant to eddy covariance measurement technique. J. Geophys. Res., 102(D11), 12789-12794, 1997.

Rannik, Ü., Aalto, P., Keronen, P., Vesala, T., and Kulmala, M.: Interpretation of aerosol particle fluxes over a pine forest: dry deposition and random errors, J. Geophys. Res, 108, 4544, doi:10.1029/2003JD003542, 2003.

Rissler, J., Swietlicki, E., Zhou, J., Roberts, G., Andreae, M.O., Gatti, L.V., and Artaxo, P.: Physical properties of the submicrometer aerosol over the Amazon rain forest during the wetto-dry season transition - comparison of modeled and measured CCN concentrations, Atmos. Chem. Phys., 4, 2119-2143, 2004, http://www.atmos-chem-phys.net/4/2119/2004/.

Rissler, J., Vestin, A., Swietlicki, E., Fisch, G., Zhou, J., Artaxo, P., and Andreae, M.O.: Size distribution and hygroscopic properties of aerosol particles from dry season biomass burning in Amazonia, Atmos. Chem. Phys., 6, 471-491, 2006, http://www.atmos-chem-phys.net/6/471/2006/.

Roberts, G. C., Andreae, M.O., Zhou, J., and Artaxo, P.: Cloud condensation nuclei in the Amazon Basin: "Marine" conditions over a continent?, Geophys. Res. Lett., 28(14), 2807-2810, 2001.

Roberts, G. C., Artaxo, P., Zhou, J., Swietlicki, E., and Andreae, M. O.: Sensitivity of cen spectra on chemical and physical properties of aerosol: A case study from the Amazon basin, J. Geophys. Res., 107, doi:8010.1029/2001JD000583, 2002.

Rosenfeld, D.: Suppression of Rain and Snow by Urban and Industrial Air Pollution, Science, 287, 1793-1796, 2000. 
Sun, J. and Ariya, P. A.: Atmospheric organic and bio-aerosols as cloud condensation nuclei $(\mathrm{CCN})$ : A review, Atmos. Environ., 40, 795-820, 2006.

Stull, R. B.: An introduction to boundary layer meteorology, Kluwer Academic Publishers, The Netherlands, 451-452, 1988.

Swap, R., Garstang, M., Greco, S., Talbot, R., and Kållberg, P.: Saharan dust in the Amazon Basin, Tellus, 44B, 133-149, 1992.

Twomey, S.: The influence of pollution on the shortwave albedo of clouds, J. Atmos. Sci., 34, 1149-1152, 1977.
Webb, E. K., Pearman, G. I., and Leuning, R.: Correction of flux measurements for density effects due to heat and water vapour transfer, Q. J. Roy. Meteorol. Soc., 106, 85-100, 1980.

Zhou, J. C., Swietlicki, E., Hansson, H. C., and Artaxo, P.: Submicrometer aerosol particle size distribution and hygroscopic growth measured in the Amazon rain forest during the wet season, J. Geophys. Res., 107(D20), 8055, doi:10.1029/2000JD000203, 2002. 